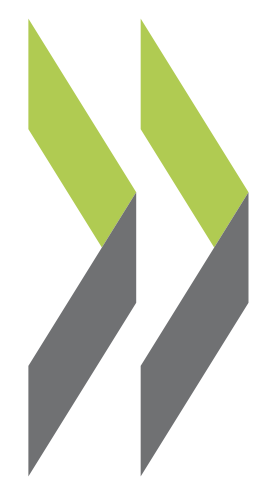

OECD Economics Department Working Papers No. 895

Reforming Austria's Highly Regarded but Costly Health System

\section{Rauf Gönenç,}

\author{
Maria M. Hofmarcher,
}

\section{Andreas Wörgötter}




\section{Unclassified}

ECO/WKP(2011)64

Organisation de Coopération et de Développement Économiques

Organisation for Economic Co-operation and Development

29-Sep-2011

ECONOMICS DEPARTMENT

English - Or. English

REFORMING AUSTRIA'S HIGHLY REGARDED BUT COSTLY HEALTH SYSTEM

ECONOMICS DEPARTMENT WORKING PAPERS No. 895

By Rauf Gönenç, Maria M. Hofmarcher, Andreas Wörgötter

All Economics Department Working Papers are available through the OECD Internet website at www.oecd.org/eco/workingpapers 


\section{ABSTRACT/RÉSUMÉ \\ Reforming Austria's highly regarded but costly health system}

The highly regarded Austrian health system delivers good quality and easily accessible services, but is costly. Its governance and funding structure is highly fragmented and it makes too much use of inpatient care in hospitals. Entry and competition opportunities are de facto limited in most health markets. The system operates therefore on a supply-driven basis, and does not have clear mechanisms to optimize spending on a cost-benefit basis. Population lifestyles are also not supportive of good health outcomes and suffer important differences between social groups, raising risks for the future. This Working Paper reviews Austrian authorities' responses to these challenges, and makes recommendations based on OECD countries' experiences. The suggested priorities are: i) more clearly assigning the performance, financing and spending responsibilities in the system, ii) enforcing a national capacity plan for publicly-funded inpatient and outpatient care, iii) introducing performance-based payment mechanisms in all services, iv) promoting the transition to "integrated care" by better balancing preventive, outpatient, inpatient, rehabilitation and long-term care, $v$ ) emphasizing healthier lifestyles and monitoring progress against national health goals (such as targets for obesity and overweight rates), and vi) better clarifying the medium-term fiscal outlook and scenarios of the system.

This working paper is a slightly revised and completed version of the special chapter of the 2011 OECD Economic Survey of Austria (www.oecd.org/eco/surveys/austria).

JEL Classification: H51; I11; I12; I18

Keywords: health care system; efficiency; public spending; health institutions and policies; Austria

\section{Réformer le système de santé très apprécié mais coûteux de l'Autriche}

Le système de santé autrichien, très apprécié, qui dispense des soins de qualité et aisément accessibles, est néanmoins coûteux. Sa structure de gouvernance et de financement est très compartimentée et le recours à l'hospitalisation est excessif. L'entrée dans le secteur et la concurrence sont de facto limitées sur la plupart des marchés de la santé. Le système est donc régi par l'offre et ne dispose pas de mécanismes précis permettant d'optimiser la dépense selon un bon rapport coûts-avantages. Les modes de vie de la population ne favorisent pas non plus de bons résultats en matière de santé et il existe d'amples disparités entre les groupes sociaux, ce qui constitue un risque pour l'avenir. Le présent document de travail passe en revue les mesures prises par les autorités autrichiennes face à ces défis et formule des recommandations fondées sur l'expérience des pays de l'OCDE. Les priorités qu'il est proposé de retenir sont les suivantes : $i$ ) définir plus précisément les responsabilités respectives au sein du système en matière de performance, de financement et de dépenses ; ii) mettre en application un plan de capacités pour les soins hospitaliers et ambulatoires financés sur fonds publics, iii) mettre en place dans tous les services des mécanismes de rémunération en fonction de la performance, $i v$ ) favoriser la transition vers une «intégration des soins » en veillant à un meilleur équilibre entre soins préventifs, soins ambulatoires, soins hospitaliers, soins de réadaptation et soins de longue durée, v) promouvoir des modes de vie sains et suivre les progrès par rapport aux objectifs nationaux de santé (comme des repères de taux d'obésité et de surpoids), et vi) mieux définir les perspectives et les scénarios budgétaires à moyen terme qui se profilent pour le système.

Ce document de travail est une version légèrement révisée et complétée du chapitre spécial de l'Etude économique de l'OCDE de l'Autriche 2011 (www.oecd.org/eco/etudes/autriche).

Classification JEL:H51; I11; I12; I18

Mots-clés : système de santé ; efficacité ; dépenses publiques ; institutions et politiques de santé, Autriche

Copyright OECD 2011.

Application for permission to reproduce or translate all, or part of, this material should be made to: Head of Publications Service, OECD, 2 rue André-Pascal, 75775 Paris CEDEX 16, France. 


\section{TABLE OF CONTENTS}

The health system performs well but is excessively fragmented and costly ........................................... 6

Health outcomes have considerably improved on the back of large resources ..................................... 6

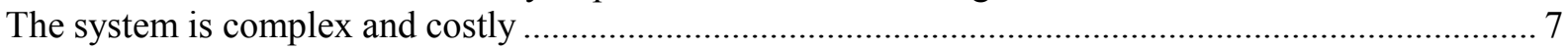

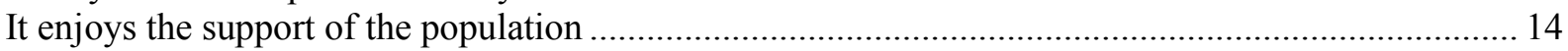

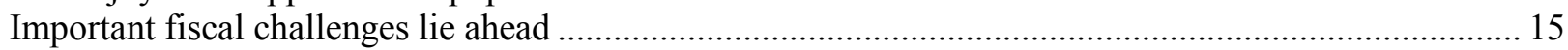

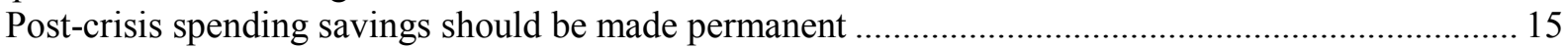

Health cost impacts of ageing may grow more than in other countries................................................ 18

Responsiveness to technological developments may create additional costs ....................................... 20

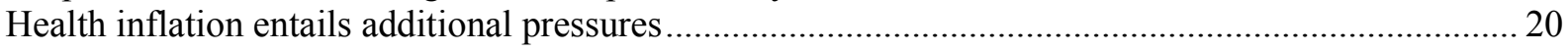

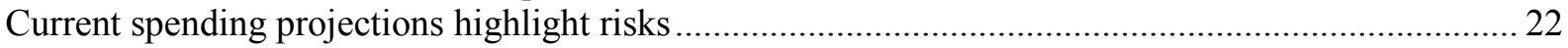

The efficiency of the system can be significantly improved, notably in the hospital sector.................... 24

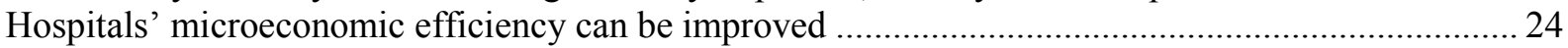

Resource utilisation can be enhanced in several Länder .................................................................... 24

The aggregate efficiency of the system falls short of best practices.............................................. 26

Key shortcomings have started to be addressed but further action is needed....................................... 27

Health care policy should also be supported by improvements in lifestyles.......................................... 37

Lifestyles are not sufficiently supportive of good health outcomes ..................................................... 37

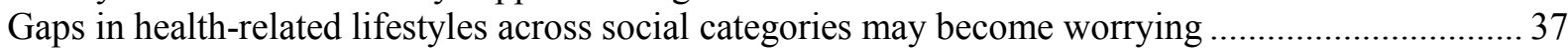

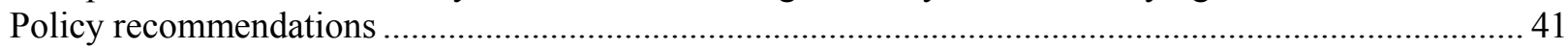

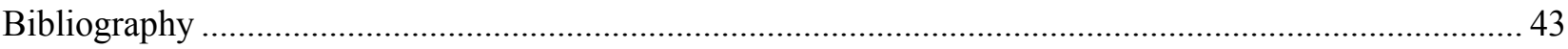

Annex A1. The future of the health system in the national policy agenda ................................................. 49

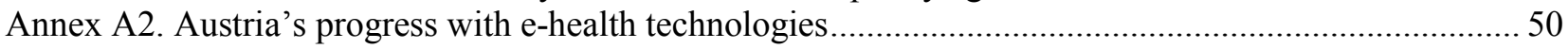

Annex A3. Some challenges with the national check-up programme ….................................................. 51

\section{Tables}

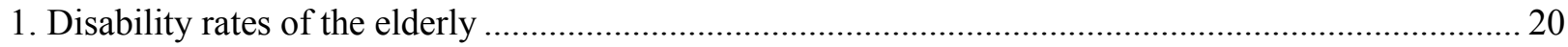

2. The spectrum of long-term health spending projections for Austria.................................................. 23

Disclaimer: This document and any map included herein are without prejudice to the status of or sovereignty over any territory, to the delimitation of international frontiers and boundaries and to the name of any territory, city or area. 


\section{Figures}

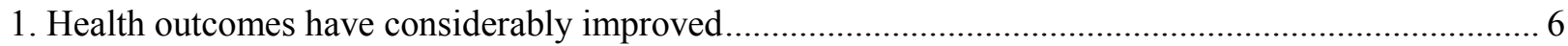

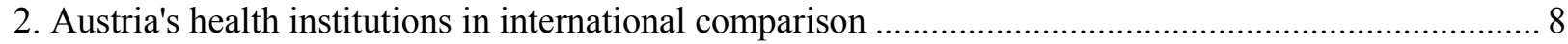

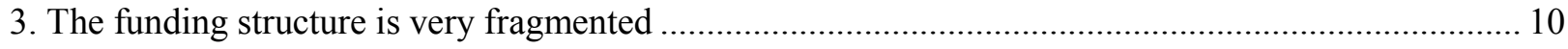

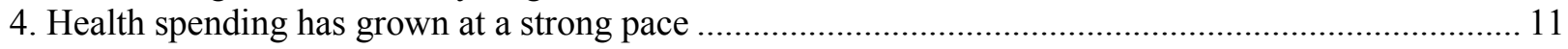

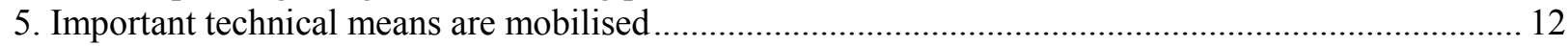

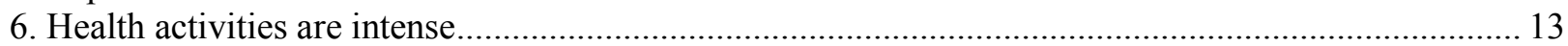

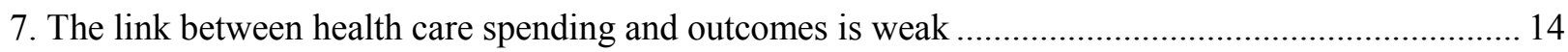

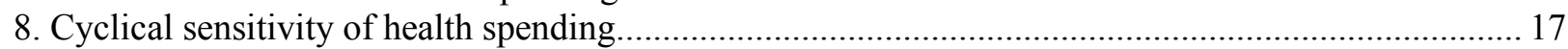

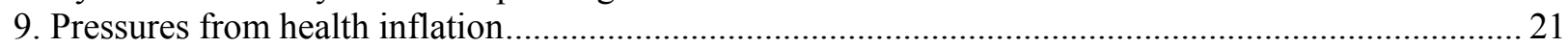

10. Comparisons between Länder suggest that there is large room for efficiency gains ........................ 25

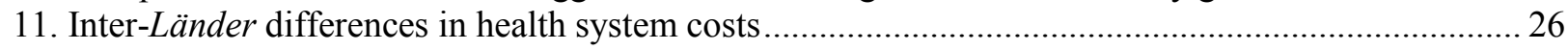

12. A comprehensive international comparison reveals room for efficiency gains ................................ 27

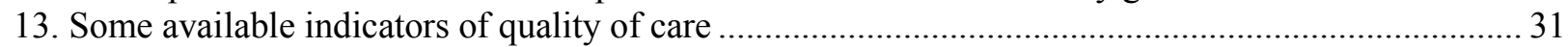

14. Other more specific indicators suggest room for improvements.................................................. 32

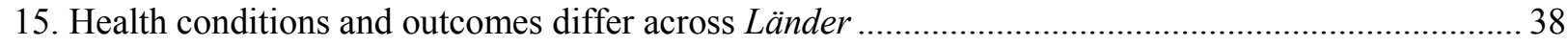

16. Health-related behaviour differ between native and immigrant groups ............................................. 39

\section{Boxes}

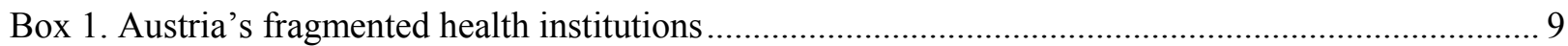

Box 2. Private payments do not necessarily undermine equity of access ............................................ 15

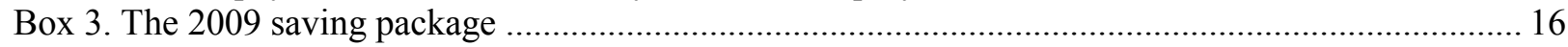

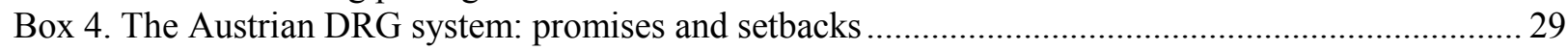

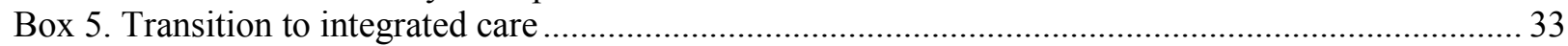

Box 6. Open contracting and payment for integrated care: lessons from other OECD countries............. 35

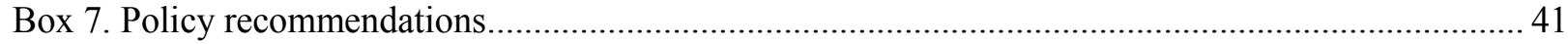


ECO/WKP(2011)64

\title{
REFORMING AUSTRIA'S HIGHLY REGARDED BUT COSTLY HEALTH SYSTEM
}

\author{
By Rauf Gönenç, Maria M. Hofmarcher, Andreas Wörgötter ${ }^{1}$
}

1. Austria dedicates very large public and total resources to health. The share of total health spending in GDP at $11 \%$ is among the highest in OECD, mainly due to high public spending (8.5\%). Health accounts for about $16 \%$ of total general government spending. The number of physicians and the number of hospital beds and high-technology health equipment per capita are among the highest in OECD. The system performs well on standard output indicators. For example, life expectancy improved drastically over the past 30 years, and exceeded 80 years in 2008, still below best performing countries but among the highest among European countries. Living conditions for the old have considerably improved, and became healthier. As a result Austrian citizens have become rather ardently attached to the existing health system, and in particular to its dense local delivery infrastructure.

2. There is growing evidence at the same time that the large resources engaged in the health system are not efficiently used. Due to a complex institutional structure, a strong bias formed toward curative inpatient care, while lifestyles and preventive behaviour in large segments of society have remained insufficiently supportive. This suggests that more efficient resource use in better optimized services, supported by more helpful lifestyles could help improve the health status of the population at less rapidly growing public costs.

3. Reforming the health system is crucial in the context of the national policy efforts to put public finances on a sustainable path. Health policymakers also want to make sure that the health system can respond to the evolving care and service needs under more stringent fiscal constraints. This working paper overviews this agenda by discussing Austria's combination of good health outcomes and costly health institutions, the short- and long-term fiscal challenges pending and the existing room for efficiency gains. It reviews the ongoing reform efforts and makes recommendations on the basis of other OECD countries' experiences.

1. Andreas Wörgötter is Head of Country Studies V Division, and Rauf Gönenç Head of Austria Desk, OECD. Maria M. Hofmarcher is Senior Researcher, Gesundheit Österreich GmbH and has been consultant for this project. This working paper relates to Chapter 2 of the OECD's 2011 Economic Survey of Austria (www.oecd.org/eco/surveys/austria). The authors are grateful for important contributions received from Austrian health officials and experts, including Clemens Martin Auer, Daniela Hüber, Silvia Türk, Richard Gauss, Jeanette Klimont, Thomas Czypionka, Claudia Habl, Ernest Pichlbauer in Vienna; Harald Gaugg, Marcus Narath, Peter Beck, Karl-Peter Pfeiffer, Eva Rasky and Margrit Sommersgutter-Reichmann in Graz; members of OECD's Economic Development and Review Committee; and OECD colleagues Andrew Dean, Bob Ford, Mark Pearson, Peter Höller, Isabelle Joumard, Michael Schönstein and Karin Fischer. Special thanks to Isabelle Joumard and Chantal Nick for running the OECD's DEA model of health sector efficiency for the Austrian Länder. Béatrice Guérard provided excellent technical assistance and thanks to Josiane Gutierrez, Pascal Halim and Nadine Dufour for excellent technical support. The views expressed in this paper reflect the personal responsibility of the authors and do not necessarily reflect those of the OECD, of the Austrian authorities or of the OECD member countries. 


\section{The health system performs well but is excessively fragmented and costly}

\section{Health outcomes have improved considerably on the back of large resources}

4. Austria's system is one of the successful examples of ambitious public health policies put in place in OECD countries in the past half-century. It has contributed importantly to the improvement of the health status of the population. Life expectancy at birth has increased by 12 years since 1960, exceeding 80 years in 2008. Gains in older ages have also been important: an Austrian woman aged 65 is expected to live an additional 21 years today (a difference of 6.4 years over 1960), and a man an additional 18 years (an improvement of 4.7 years). Living conditions at old ages have improved and have become healthier (Figure 1).

Figure 1. Health outcomes have considerably improved
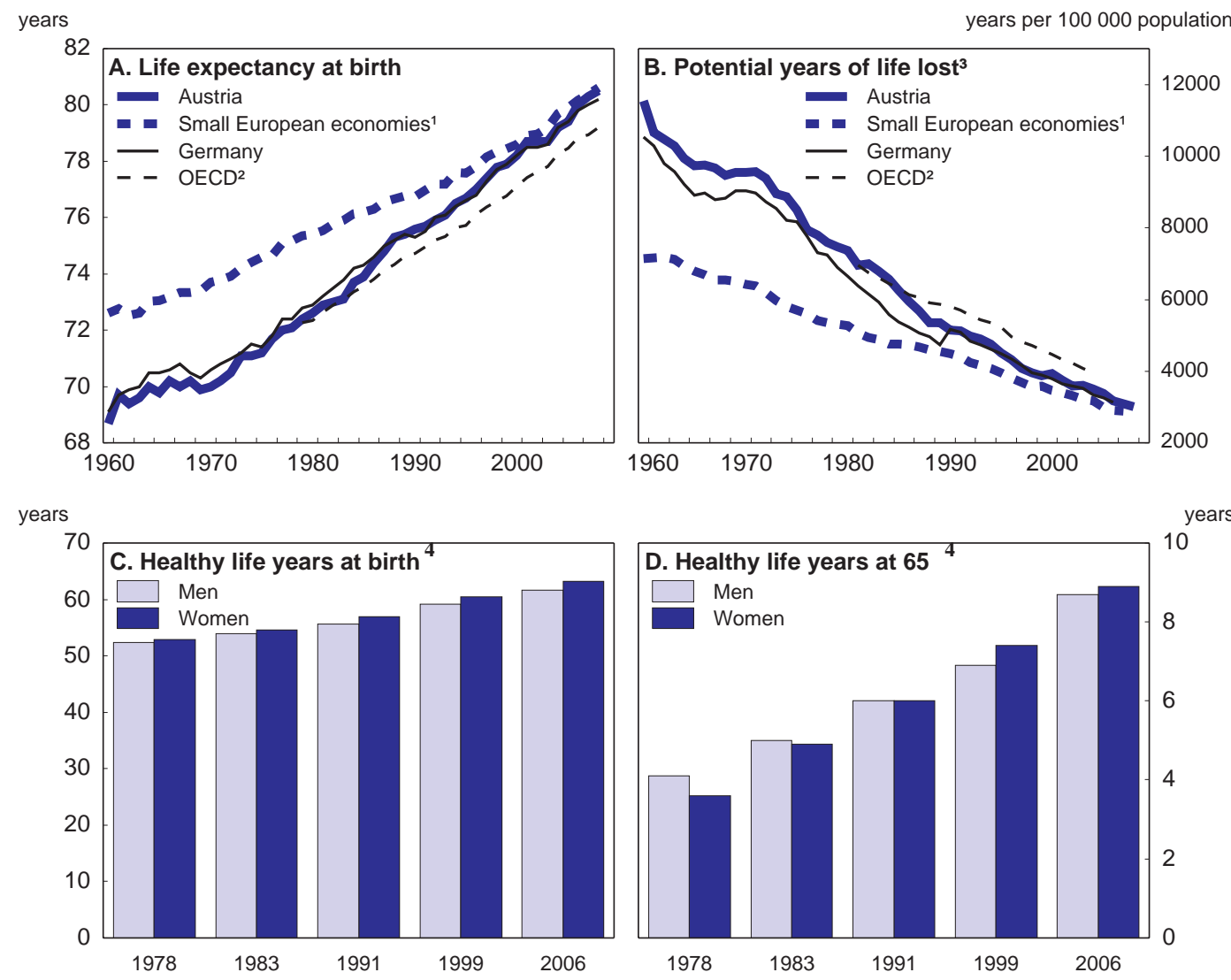

1. Arithmetic average of other small European high income economies: Denmark, the Netherlands, Sweden and Switzerland.

2. Arithmetic average over OECD countries excluding Turkey in panel $B$.

3. Arithmetic averages between males and females. Potential years of life lost is a summary measure of premature mortality which provides an explicit way of weighting deaths occurring at younger ages, which are, a priori, preventable.

4. Healthy life years indicator measures the number of remaining years that a person of a certain age is expected to live without disability. It is actually a disability-free life expectancy.

Source: OECD Health Data 2010 and Eurostat, Structural indicators on health; and OECD calculations. 


\section{The system is complex and costly}

5. At the same time, the Austrian health system is much more complex and fragmented than in other OECD countries. Constitutionally, the federal government is in charge of all areas of the health care system but delegates an important part of its responsibilities to the 9 provinces (Länder), and another part to the social insurance funds (Sickness Funds). ${ }^{2}$ The Länder are in charge of developing and maintaining an adequate hospital infrastructure, without funding it from their own tax revenues. Transfers from the federal government agreed under five-yearly "constitutional agreements" fulfil this purpose, under relatively flexible rules open to political bargaining. The federal government therefore finances a substantial share of costs without exerting any influence on the utilisation of the funds. The 19 Sickness Funds are in turn delegated the task of contracting for ambulatory care, pharmaceutical products and medical devices, that they fund from the employer and employee contributions that they collect. Sickness Funds also participate in the funding of hospitals by transferring a fixed share of their resources $(35 \%)$ to Länder' hospital funds. ${ }^{3}$ This highly segmented funding structure weakens incentives for optimisation and makes providers the key drivers of the system. The provision of inpatient services is mainly assured by Länder owned hospitals, and of outpatient services mainly by independent physicians permanently contracted by Sickness Funds through their "regional physician chambers" (Box 1).

6. A comprehensive review of national health systems by OECD helped highlight the institutional specificities of the Austrian health system in international comparison (OECD, 2010 a). This review confirmed that, as a result of the fragmentation discussed above, Austria's system is highly decentralized toward sub-central authorities and social health insurers, although not consistently. As a result, there is limited room for strategic prioritization and priority-setting, while budget constraints are not managed actively and explicitly. Also, price signals do not play an important role and there is no gate-keeping function. In this environment, public health spending has grown more rapidly than in most other OECD countries and the share of public health spending in GDP reached one of the highest levels in OECD. On the other hand, the degree of user information on the quality and prices of services remains relatively limited and user choice among alternative providers is limited in parts of the system (Figure 2 and Box 1).

2. The Constitution stipulates that responsibilities for almost all areas of the health care system - with a few exceptions in legislation and implementation - lie with the Federal government. Responsibility for enacting legislation and implementation lies with the nine provinces (Länder), while the sanitary supervision of the hospital sector remains the responsibility of the Federal government.

3. "Land Health Funds" financing local hospitals were set up in each Land as part of health care reforms in 2005. 
Figure 2. Austria's health institutions in international comparison

\section{A. Gate-keeping ${ }^{1}$}

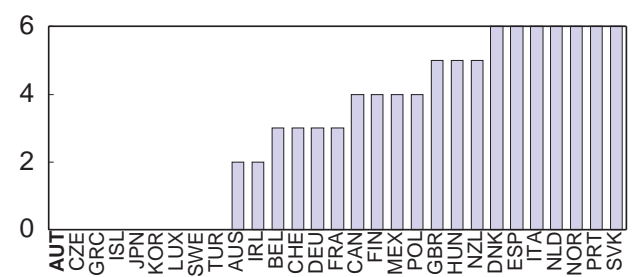

C. Patient choice among providers ${ }^{3}$

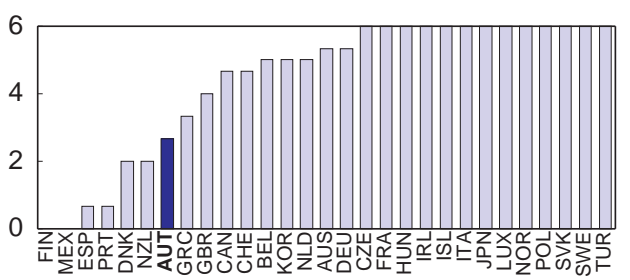

E. Depth 5

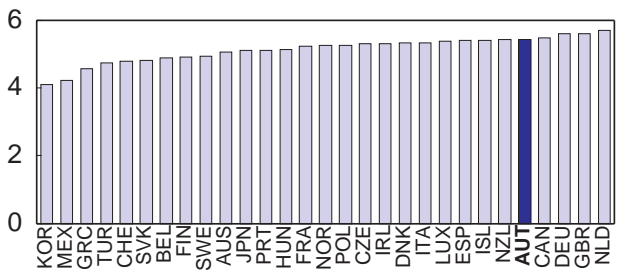

G. Setting of priorities 7

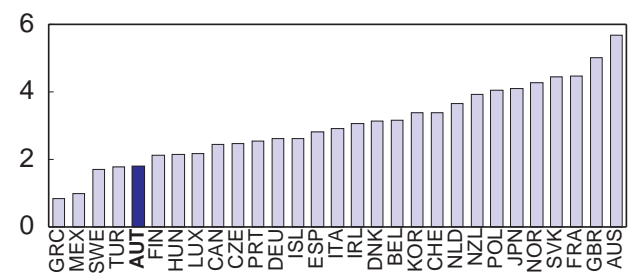

B. Price signals on users ${ }^{2}$

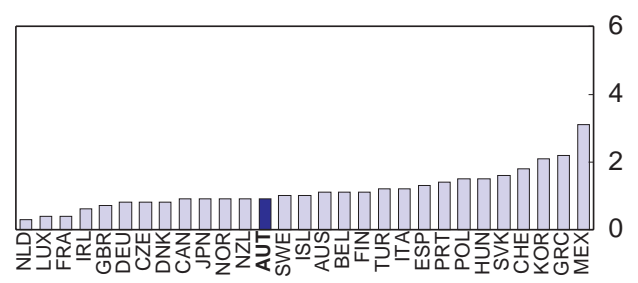

D. User information on quality and prices 4

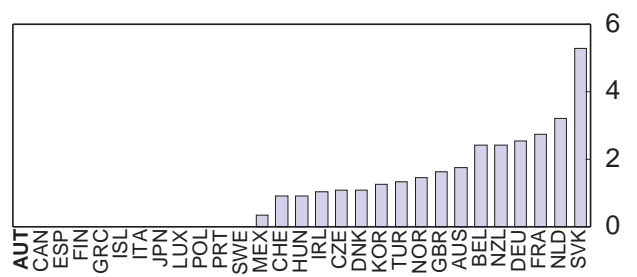

F. Stringency of the budget constraint 6

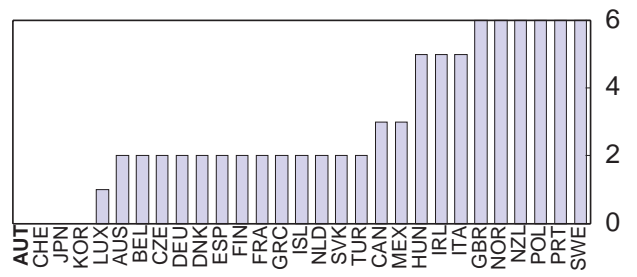

H. Consistency in responsibility assignment across levels of government 8

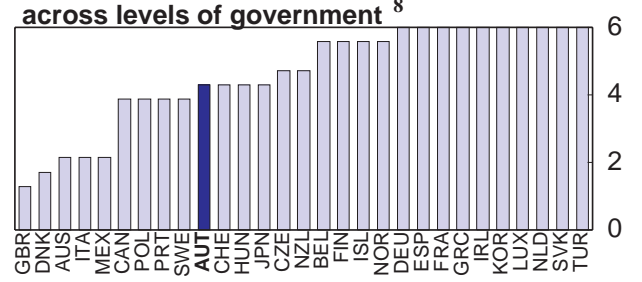

1. A "0" score is attributed to countries where patients face no obligation or incentive to register with a General Practitioner (GP) and to obtain referral to access secondary care.

2. The score corresponds to the share of "out-of-pocket" payments in total health expenditure, rescaled from 0 to 6.

3. A "0" score is attributed to countries where patients face severe limitations when choosing a primary care physician, a specialist and a hospital.

4. A high score is attributed to countries where information on the quality of care and on price allows patients and/or purchasers to discriminate among providers.

5. The depth of coverage represents the level of the costs covered for key goods and services included in the basic benefit package and the actual level of coverage by health insurance (public and private).

6. A "0" score is attributed to countries with a soft budget constraint.

7. The scores reflect whether a health benefit basket is defined, criteria taken into account to define it, the definition and monitoring of public health objectives.

8. The lower the score, the lower the consistency (clarity of responsibility and lack of overlap) in responsibility assignment across government levels.

Source: OECD (2010), Health Care Systems: Efficiency and Policy Settings. 


\section{Box 1. Austria's fragmented health institutions}

The fragmented pattern of the governance and funding structure of the Austrian health system was already reviewed in the 1997 and 2005 OECD Economic Surveys of Austria. There are four sources of fragmentation rooted in the institutional design of the system, making Austria's health sector overly supply-driven, with limited incentives and capacity to respond to the demands of policymakers and market forces (OECD, 1997 and 2005).

First, public health spending is divided between general government $(42 \%)$ and social insurance funds $(58 \%)$ (Figure 3). On the part of the government, Federal, Länder and municipal levels are simultaneously involved, to fund mainly hospital services. Social insurance finances other spending such as outpatient care by independent physicians, pharmaceutical costs, and part of the hospital costs. In this setting, no party plays the role of a "principal", to strategically steer the system. An illusion is also created, notably among local policymakers and populations, that health services are free and the health sector can ultimately operate outside economic constraints.

Second, each resident is registered with one of the 19 "Sickness Funds", on basis of either region of residence or branch of employment. Funds offer somewhat different basic packages. There is only a rudimentary risk equalization system between them (on basis of the age structure of membership) but no yardstick or direct competition.

Third, there is a very strong bias in the health sector in favour of hospital services. As the costs of both inpatient and outpatient care provided by hospitals are largely funded by the government, Sickness Funds have a distorted view of hospital costs, and no incentive to take them fully into account. At the same time, Länder governments have an interest in maintaining hospital capacity at high levels. Residents appreciate round-the-clock hospital services near where they live, and make intensive use of them.

Fourth, entry and competition are de facto limited in markets for publicly-funded health services and goods. Most hospitals are local monopolies. Ambulatory services by independent physicians are offered by "contracted networks" of generalists and specialists, which are co-managed by their respective professional associations, which exert monopolistic power. Pharmaceutical and other medical goods producers operate under restrictive regulatory frameworks which reduce competition. This may explain the relatively low share of generic pharmaceutical products.

The supply of various health services and products is indeed organised through different arrangements:

i) inpatient care is provided by a majority of Länder-owned and a minority of private non-profit hospitals, with funding from the federal government and Sickness Funds;

ii) generalist and specialist outpatient services are provided by physicians contracted by Sickness Funds, through collective regional contracts with regional medical chambers, and, by the outpatient wards of hospitals;

iii) drugs and medical aids are listed (referenced) by the federal government, with relatively few generic products authorized; and

iv) long-term care is provided by Länder governments, in regulated institutions. A new "long-term care fund" (Pflegefonds) is now being put in place at the federal level to contribute to the financing of services.

This segmentation in the organisation of supply creates firewalls between different types of services. In each area, provider groups (notably through their professional organisations) gain a high influence on the types of services provided and their prices.

The structure remains heavily centred on hospital services. Austria tops OECD countries for the number of acute care beds per capita (after Japan and Korea). There were 183 acute care hospitals in 2006, providing 52894 beds. $92 \%$ of this capacity is in Länder-financed hospitals; $64 \%$ of the capacity is in directly Länder-and-municipality owned hospitals; $17 \%$ in three university hospitals; $8 \%$ in 'invalidity and work accident hospitals; $16 \%$ in institutions ran by religious congregations and $6 \%$ in private profit making hospitals. The majority of beds are acute care beds and there is no gate-keeping filtering access to them. 


\section{Figure 3. The funding structure is very fragmented}

2008 (or latest available)

A. Public health spending

General government excluding social insurance $\%$ of public health spending

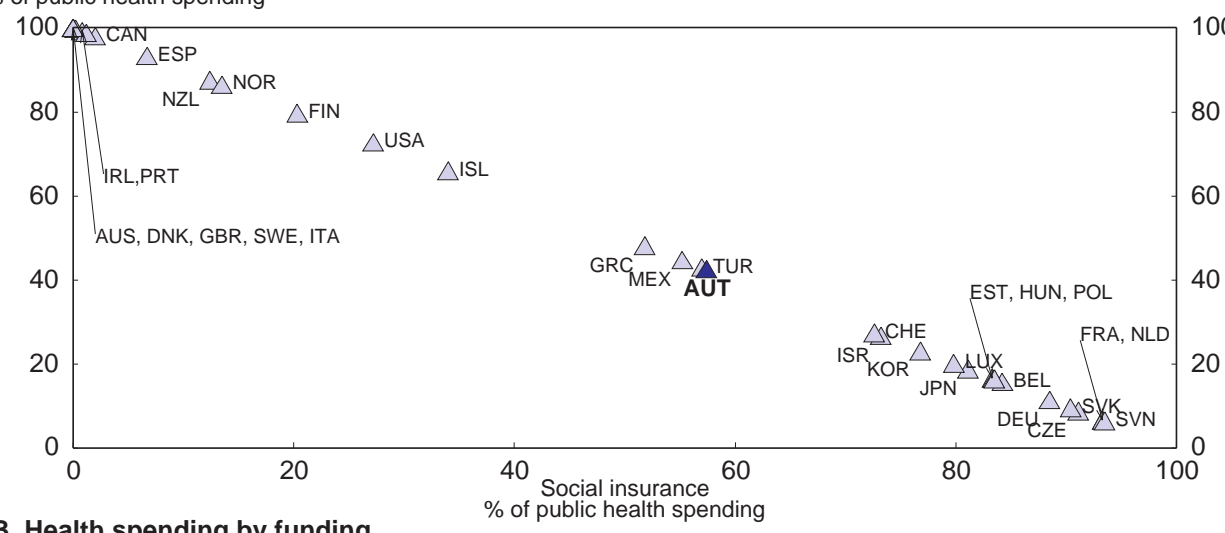

B. Health spending by funding

$\%$ of total health spending
Austria
Germany

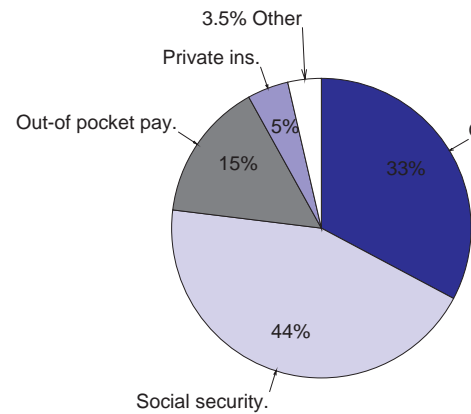

Sweden

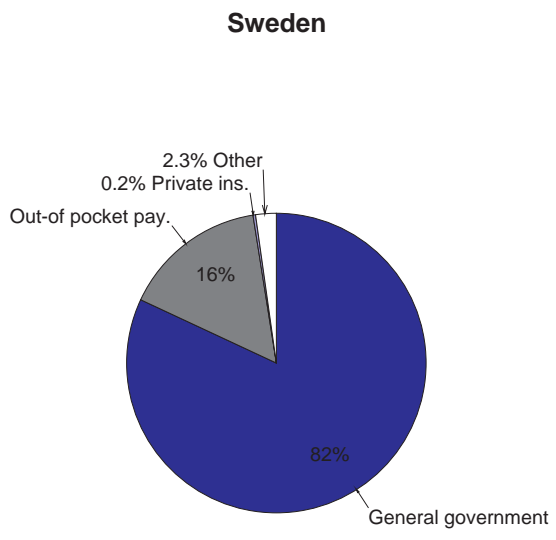

$$
\text { Austria }
$$

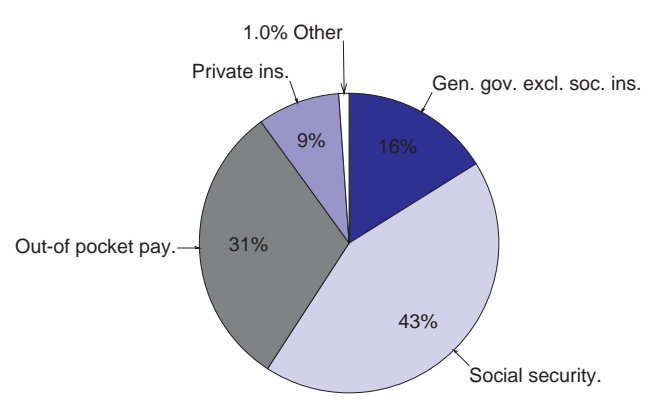

Source: OECD Health Data 2010. 
7. This complex system covers the whole population (98.7\%) and provides access to "all necessary services". 4 The standard functions of public health insurance are available at particularly high reimbursement rates. ${ }^{5}$ Austria is indeed one of the two OECD countries where the publicly funded insurance package is defined in relatively open-ended ways. The package has expanded through time, in response to technological developments and societal demands. For instance, psychotherapy and in vitro fecondation have been introduced in the 1990s. Access to new vintages of pharmaceuticals is also rather generously provided.

Figure 4. Health spending has grown at a strong pace
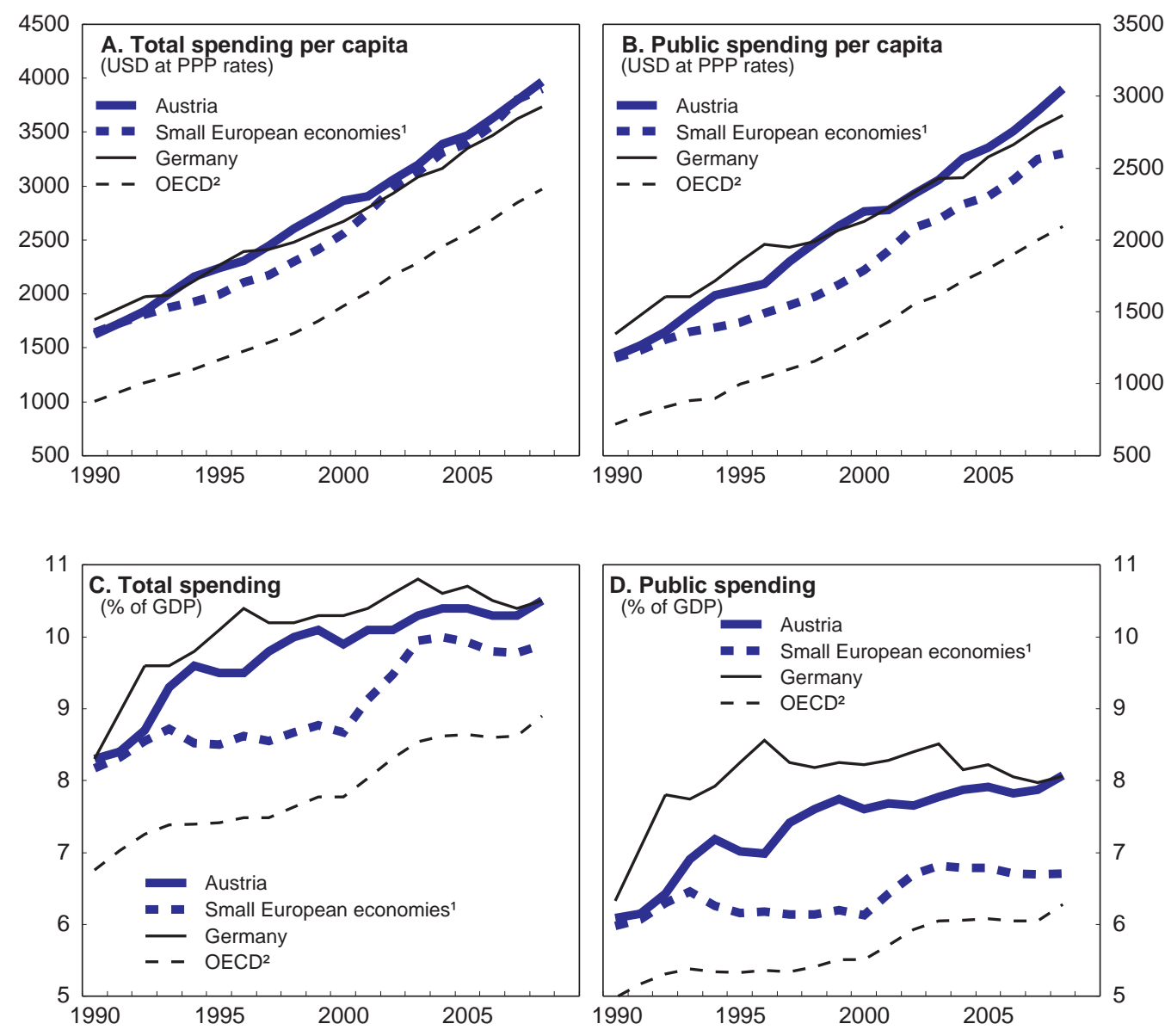

1. Arithmetic average of other small European high income economies: Denmark, the Netherlands, Sweden and Switzerland.

2. Arithmetic average over OECD countries.

Source: OECD Health Data 2010 and OECD calculations.

4. As termed in the social security law.

5. Reimbursement rates in all ten standard functions of public health packages are each the relatively highest in the OECD (acute in-patient care, outpatient primary care, outpatient specialist care, clinical laboratory tests, diagnostic imaging, physiotherapist services, pharmaceuticals, eyeglasses and contact lenses, dental care and dental prostheses) (Paris et al., 2010). 
8. As a consequence of this broad coverage of health needs, Austria ended up dedicating more fiscal resources to public health than other high-income European countries such as Sweden, Denmark, Netherlands and Switzerland. The share of total health spending in GDP, at about $11 \%$, and the share of public health spending in GDP, at 8.5\%, are now among the highest in OECD. ${ }^{6}$ These levels were reached after a long period of stronger growth of spending than in other OECD countries (Figure 4).

Figure 5. Important technical means are mobilised
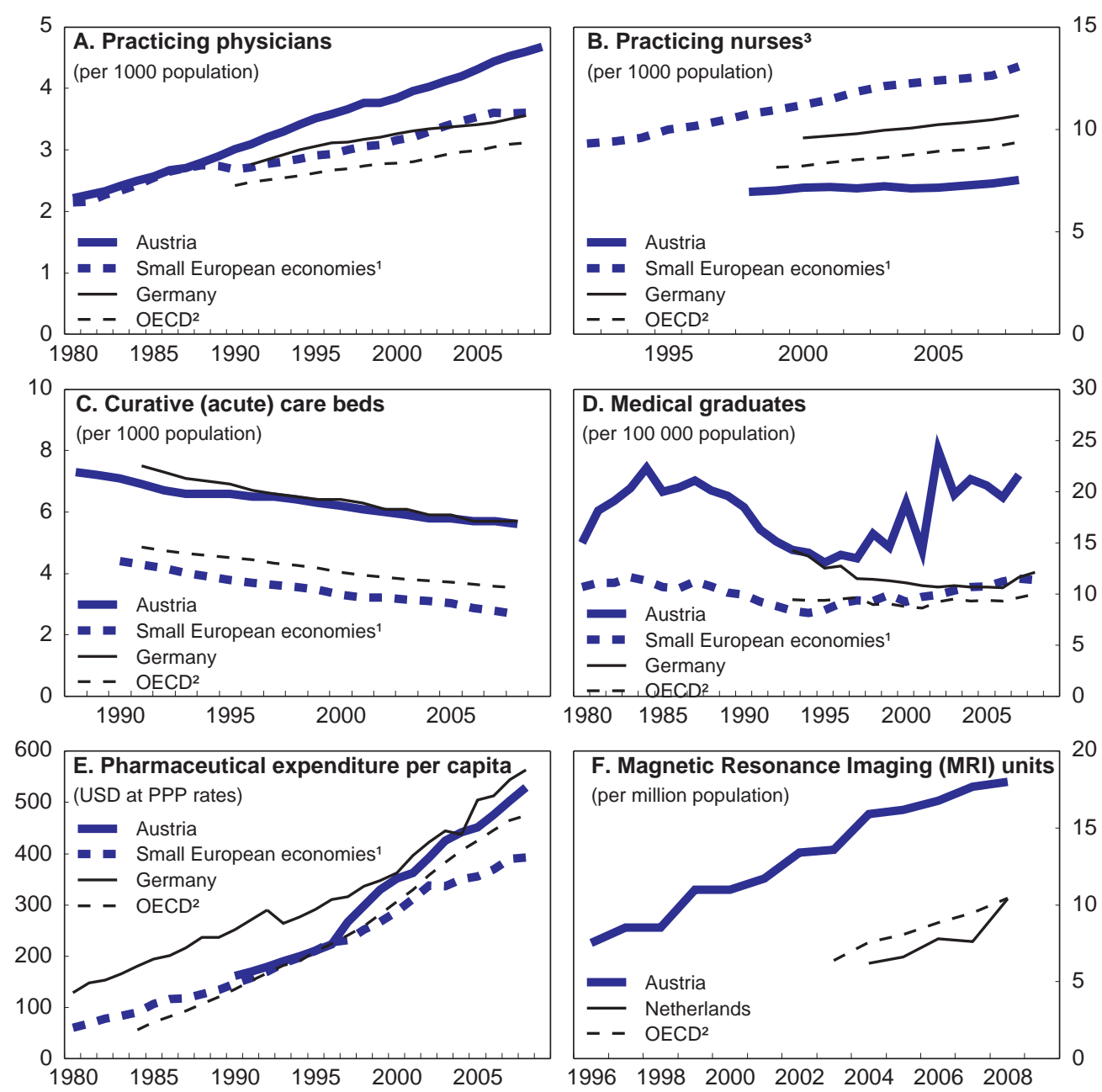

1. Arithmetic average of other small European high income economies: Denmark, the Netherlands, Sweden and Switzerland except the Netherlands in Panel A.

2. Arithmetic average over OECD countries. The number of countries included in the OECD aggregate varies between 20 and 30 according to panels, depending on data availability.

3. International comparisons of nurse numbers suffer from definitional differences, and in certain instances only hospital nurses are reported. However, there is agreement that there is an undersupply of nurses in the Austrian health system.

Source: OECD Health Data 2010.

6. These figures follow the convention taken in all OECD work on health and includes spending for long-term care, as reflected in the OECD Health database. 
9. Consequently, large human and technical means are mobilised in the health system. The number of acute care beds per population is one of the highest in the OECD and so is the number of acute hospital admissions. The number of generalist and specialist physicians and the rate of high technology diagnostic and treatment equipment per capita have become very high. ${ }^{7}$ The consumption of pharmaceuticals registered one of the fastest growth rates in the euro area. ${ }^{8}$ Austria has also experienced the largest increase in the number of medical students in the 2000s (also as a result of an inflow of foreign students, notably from Germany). This large resource base underpins a more intense health activity than in other OECD countries (Figures 5 and 6).

Figure 6. Health activities are intense

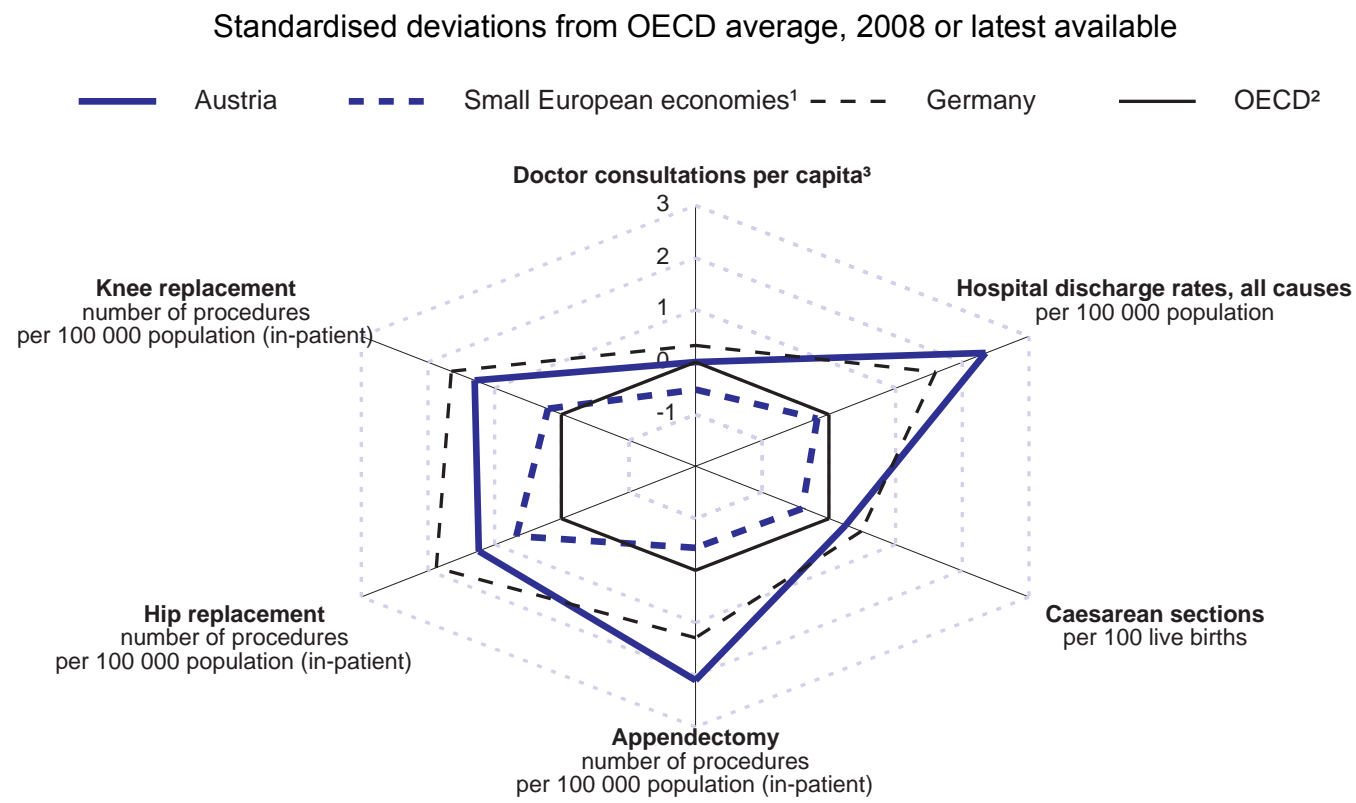

1. Arithmetic average of other small European high income economies: Denmark, the Netherlands, Sweden and Switzerland except Sweden for caesarean sections.

2. Arithmetic average over OECD countries except Chile and also excluding - for doctor consultations: Ireland, Italy and Norway; for caesarean sections: Greece, Japan and Sweden; for appendectomy: Czech Republic, Japan, Korea and Turkey; for replacement of hip: Czech Republic, Italy, Japan, Slovak Republic and Turkey; and for replacement of knee: Czech Republic, Estonia, Greece, Japan, Norway, Poland, Slovak Republic and Turkey.

3. Detailed and more regularly updated data on doctor consultations is available in Austria, based on electronic (e-card) records.

Source: OECD Health Data 2010.

10. However, the link between resources devoted to the health system and actual health outcomes remains at first sight not strong. The recent OECD overview positioned countries in terms of the amount of resources that they dedicate to health and the results that they obtain (proxied in a first stage through the average life expectancy of the population). This, and other indicators of efficiency are reviewed later in the working paper, yet this first hint suggests that serious efficiency shortcomings may be characterizing Austria's complex and resource-intensive health institutions (Figure 7).

7. In Austria, the number of magnetic resonance imaging devices (MRIs) increased from 7 per million population in 1996 to 18 in 2008. Well above the OECD average of 12.6. Only Japan, US, Iceland and Italy have higher figures.

8. At $3.4 \%$ per year in 2009?, against 3.3\% in Denmark, $3 \%$ in Sweden, $2.9 \%$ in Germany and $1.1 \%$ in Switzerland. 
Figure 7. The link between health care spending and outcomes is weak

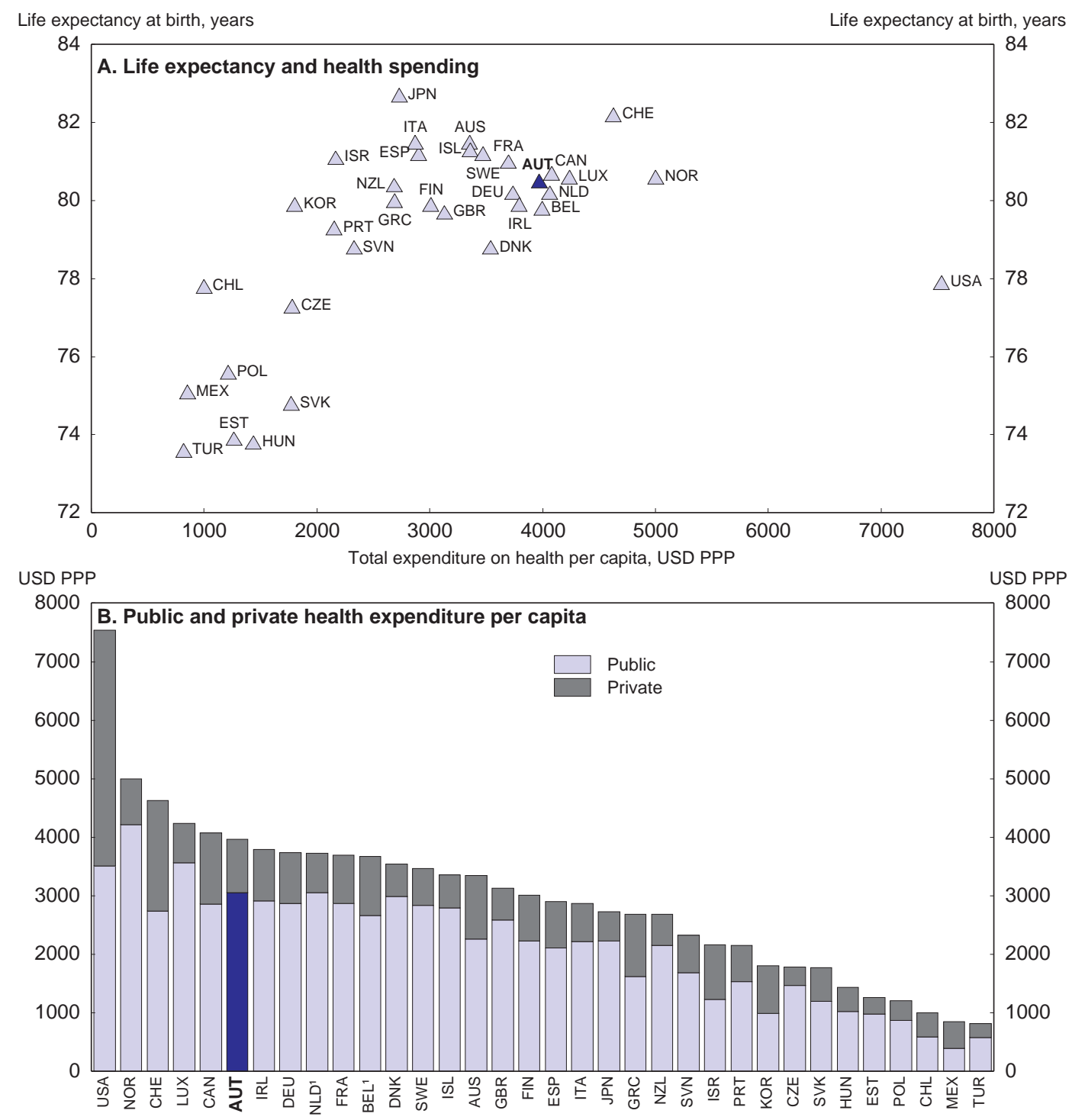

1. Current health expenditure.

Source: OECD Health Data 2010.

\section{It enjoys the support of the population}

11. Nonetheless, this commitment of resources helped Austria achieve a very high degree of equity of access to services. All the main international indicators of equity in health care confirm this achievement: $i$ ) only $2 \%$ of the population at the lowest income quintile report any difficulty of access to health services); ii) differences in contracted physician density across Territorial level 2 regions are very small; and iii) differences between women in different wealth quintiles in using cervical and breast cancer screening are very low (OECD, 2009). These outcomes are obtained despite private payments playing a relatively large role in financing (Figure 3), thanks to a system of exemptions which helped maintaining access despite an eventual inability to pay (Box 2). 


\section{Box 2. Private payments do not necessarily undermine equity of access}

The share of private contributions in the financing of health services was $23 \%$ in 2008 in Austria, above OECD and EU averages. They include out-of-pocket payments (direct cost-sharing), co-payments (indirect cost-sharing), and premia for private insurance. Exemptions however minimize exclusion risks:

Out-of-pocket payments fund services which are not in the benefit catalogue of Sickness Funds. The main items are special medicines, comfortable rooms in hospitals, and fixed dentures. For patients deserving social protection, exemptions are granted.

Co-payments are participations by patients to the cost of standard services that they use. They include payments to independent physicians without a contract with Sickness Funds. These physicians practice unregulated fees, and are reimbursed at four fifths of the normal fees of contracted physicians, the patient paying the reminder. Members of certain Sickness Funds (of civil servants, farmers, the self-employed and the employees of Austrian Railways) contribute a further co-payment for each physician visit. Everybody also contributes a limited fixed amount for each prescription and for each hospital stay, under a means-tested exemption. On top of these exemptions, a further cap was applied to pharmaceutical co-payments since 2008.

Private insurance secures cash benefits during hospital stays (which is an essential source of guaranteed income for the self-employed). It also finances access to non-contracted physicians, and to better accommodation in hospitals. One third of the population has such complementary insurance - half of them being self-employed. The number of private insurance policies has been falling since the 1990s.

12. As a result, the population shows a very strong attachment to the existing health institutions as reiterated by successive cohorts of opinion surveys ${ }^{9}$ (Annex A1).

\section{Important fiscal challenges lie ahead}

13. Austria has a compelling short- and long-term fiscal consolidation task, as reviewed in the 2011 OECD Economic Survey of Austria (OECD, 2011a). As public health is one of the largest single public spending items (amounting to about $16 \%$ of total general government spending) it is essential to exploit any available room for savings existing in the health system. This working paper argues that room exists for savings - and started to be exploited by the authorities - while longer-term spending pressures are also serious. Beyond immediate savings associated with the post-crisis fiscal consolidation, structural reforms to contain spending are necessary to make these short-term savings sustainable.

\section{Post-crisis spending savings should be made permanent}

14. The 2008-09 economic crisis affected the finances of the Austrian health system mainly by slowing down the revenues of Sickness Funds. As most of these funds' expenditures are independent from cyclical conditions, several of them faced financial strains and accumulated debt. ${ }^{10}$ Federal authorities responded by taking the lead in orchestrating a saving programme and offered some financial incentives

9. There are certain indications that this high degree of accessibility came under pressure in the recent period. Imbalances between demand and supply have emerged in certain parts of the health system. They show in "queues" for certain publicly-funded treatments. There are indications that patients with private insurance can circumvent them, sometime in non-transparent ways. A recent review by Transparency International Austria reported: i) pent-up demand for certain restrained drugs and implants; ii) evidence of under-thetable payments to professionals controlling access to these resources; and iii) pressure faced by many patients to purchase for-fee services as a way to get access to publicly funded services (quoted by Sanofi-Aventis, 2010).

10. As of early 2009, Regional Sickness Funds had accumulated a total debt of about EUR 1.2 billion. 


\section{ECO/WKP(2011)64}

for its implementation. After in-depth negotiations with the multitude of actors which co-fund and co-manage the system, a package was finalized. It left out the hospital sector for which spending responsibility remained with the Länder (Box 3).

\section{Box 3. The 2009 saving package}

During a special retreat in February 2009 after the new government took office in December 2008, coalition partners pledged to safeguard the budget balances of the Sickness Funds in the crisis, provided that they commit to achieve savings. ${ }^{11}$ The support package was to offer cash subsidies to Sickness Funds, and a government commitment to write-off gradually their recently built-up debt.

A so called Structural Fund for Health Insurance was created in September 2009 to manage the scheme. A Debt Forgiveness Law was also adopted. The package was innovative as, for the first time, it strengthened federal government's leverage on the social insurance sector. Federal authorities allocated subsidies of EUR 100 million per year to Sickness Funds, and committed to write off EUR 150 million of their debt per year between 2010 and 2012. The two measures amounted together to about $1.7 \%$ of Sickness Fund's aggregate annual budget. In the 2011, confronted with further fiscal constraints, the government reduced direct subsidies by more than half, to EUR 40 million per year, but committed to maintain this allocation until 2014.

In return, the Federation of Sickness Funds (Hauptverband) promised to submit a road map for cost containment (Sanierungskonzept). This scheme was to be negotiated with the suppliers of services, in particular with the doctors' professional association (the medical chamber). The finalized roadmap stipulated cost savings amounting to EUR 1.7 billion between 2010 and 2013. Savings of 197 million were to be achieved in 2010 (1.4\% of annual Sickness Fund spending), 361 million in 2011, 510 million in 2012 and 657 million in 2013. To make targets stringent, shifting savings between funds and across years was banned. ${ }^{12}$

Early outcomes of this package appear promising. In the first year of the Structural Fund's implementation, 2010, the Ministry of Health reported that cost savings exceeded expectations by as much as $50 \%$. The Federation of Sickness Funds reports that out of a total health insurance sector budget of EUR 14.6 billion, they expect a surplus of EUR 175 million. Before the saving package it was projected that funds' combined deficit would reach EUR 376 million. This surplus was obtained thanks to: i) reductions in prescription drug spending (the biggest saving item); ii) cost-control with contracted physicians; and iii) savings in technological devices and equipment. Going forward, the 2011 federal budget report mentions that additional savings will be achieved in: i) ambulatory care, ii) data centres and information technology, and iii) procurement and administrative costs. However, hospital costs, which generate $55 \%$ of total public health expenditure have not been included in the scheme.

The Federation of Sickness Funds recently emphasised this issue. According to the Federation, underlying spending dynamics in the health sector remain worrying: in 2013, additional spending of EUR 3.2 billion are projected (an increase of $10 \%$ over 2010), due mostly to additional hospital spending. The Federation suggested that more structural measures should be envisaged for the continuing implementation of the saving package, including: i) unifying the hospital law (which is fragmented into 9 different Länder laws); ii) merging federal and Sickness Fund resources presently earmarked for hospital funding and using them more effectively for efficiency gains; and iii) enhancing the transparency of spending in hospitals. The Federation said that if assertive measures are taken in these areas, bigger savings than the targets set in the 2009 saving package would be within reach.

11. The package covered the nine regional (Länder) funds, which together insure $80 \%$ of the Austrian population. The few smaller national branch funds are also requested to report cost savings but their incentive to do so is limited as they do not participate in the reward scheme.

12. Certain aspects of the package were criticized for not being fully transparent and equitable. First, subsidies were distributed according to size of membership (number of the insured in each Fund), without consideration to the specific risk structures and spending pressures faced by each fund. Second, they did not reward specific saving efforts, as they were not proportional to the cost containment delivered by each fund. Certain individual Sickness Funds challenged, on this ground, the fairness and even the constitutionality of the scheme (Upper Austria, Salzburg and Vorarlberg Funds were leading this opposition, because they were in surplus and had not accumulated debt to write-off). It was not clear however if the superior financial status of these regional funds was due to their higher efficiency and performance, or to their more favourable membership and risk structure. 
15. Early evidence on the enforcement of the 2009 saving plan suggests that targets will have been attained in 2009 and 2010. However, there are also concerns that pent-up spending pressures remain in the system, and might unfold from 2011. According to the estimations used by the authorities, Sickness Funds' aggregate spending (which represents about $50 \%$ of total public health spending) grew only by $2.3 \%$ in nominal terms in 2009 , and by $2.1 \%$ in 2010 . However, expenditure growth is projected to accelerate to $3.4 \%$ in $2011,2.5 \%$ in 2012 and 3.3\% in 2013. These tentative projections hint therefore at a risk for the 2009 Saving Package to be successful in its first phase of implementation, but, in the absence of additional structural reforms and measures, notably in the hospital sector, to stall against the more ambitious targets of subsequent years. The savings achieved in the crisis could be reversed when fiscal conditions improve.

16. This risk is corroborated by Austria's past experience with the cyclical pattern of public health spending (Figure 8). It appears indeed that total public health spending displays a much higher responsiveness to the macroeconomic cycle in Austria than in countries with similar fiscal structures such as Germany, Switzerland, Sweden and Denmark. This capacity of the system to adjust to fiscal circumstances is obtained through three genuine mechanisms: annual negotiations between Sickness Funds and doctors' and pharmaceutical producers' associations on prices and volumes; the budgeting system of hospitals which is based on cyclically-dependent transfers from the federal government and from Sickness Funds, inciting them to manage spending pro-cyclically; and, finally, new funding opportunities created by the establishment of off-budget regional hospital companies, which may recourse to non-budget borrowing when fiscal resources dry up and reduce general government funding in accounting terms. These factors of pro-cyclicality may have been in play in the exceptional circumstances of the 2008-09 crisis and may have contributed to the success of the savings package. Yet, the very same pro-cyclicality suggests that, in the absence of structural reforms, spending could accelerate when the economy recovers.

Figure 8. Cyclical sensitivity of health spending
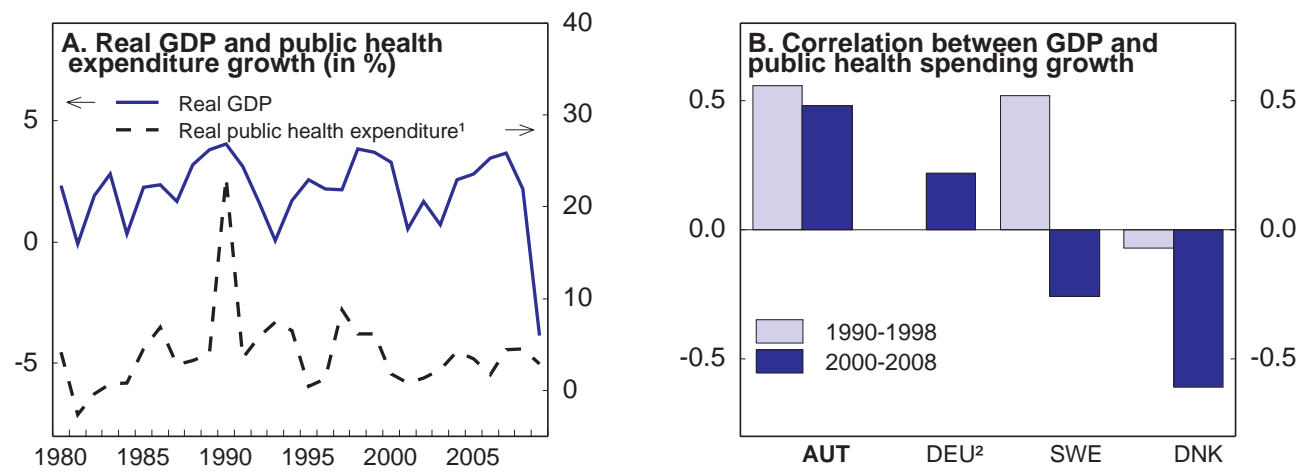

1. From 1990, health expenditure is calculated according to SHA (System of Health Account), for earlier reporting years only national accounts estimates are available. The break between 1989 and 1990 therefore occurs according to the change from SNA definitions to SHA definitions.

2. Correlation between 1990-98 not available for Germany.

Source: OECD Health Data 2010 and OECD Economic Outlook database.

17. Efforts to rein in pharmaceutical spending in mid-2000s illustrate this risk. An indicative annual growth ceiling of 3-4\% was set for public pharmaceutical spending in 2005, in consultation with doctors' associations and pharmaceutical producers. However, after a first phase of compliance, pharmaceutical spending soared again when the economy recovered in 2007 and 2008, without any check. In the same vein, the pharmaceutical industry agreed to reduce profit margins voluntarily in the framework of the 2009 saving plan, to save EUR 200 million in pharmaceutical spending (6\% of yearly pharmaceutical spending). A new law also required physicians to prescribe the most economical available drugs (ökonomische 
Verschreibweise), without, however, asking pharmacists to convert prescriptions to their cheapest equivalents, as in some other countries. ${ }^{13}$ This type of arrangements raise the issue of the sustainability of the savings obtained through such ad hoc consensual agreements.

18. Independently from cyclically-motivated consolidation needs, important medium-to-long term spending pressures loom for the Austrian health system. As in other OECD countries, they arise from three sources: $i$ ) the ageing of the population (e.g. growing share of older cohorts with higher health spending); ii) technological progress which generates more costly medical treatments and products; and iii) increases in the relative prices of medical goods and services. All three factors play a particularly important role in Austria and call for policymakers' special attention. If these underlying trends are not fully taken into account, ex post spending cuts may become necessary when they hit, leading to suboptimal rationing and arbitrages in the health system.

\section{Health cost impacts of ageing may grow more than in other countries}

19. As everywhere, cohort-specific public health expenditure rises with age in Austria. Per capita expenditure in the 85-89 years old cohort is, for example, five times higher than in the cohort 35-39. In $2010,17.6 \%$ of the population was above 65 , but will reach almost a quarter in $2030 .{ }^{14}$ The impact on health spending of this shifting cohort structure is now well known and does not differ from other countries. ${ }^{15}$ It is estimated that it will entail a relatively confined increase in the share of public health spending in GDP (Table 2 below).

20. Another factor will compound the impact of ageing on health care spending in Austria: The country's formal commitment to take responsibility for dependant old-age people's care needs in a broad sense, combining both healthcare and dependency help, and which should generate demand for new combinations of health and nursing services.

21. Austria has taken more comprehensive protection commitments vis-à-vis its elderly population than in most other OECD countries, irrespective of the financial means of beneficiaries. With the passing of the 1993 federal Long-Term Care Benefit Act, it reacted very early to the coming demographic changes. This Act offers, as a universal benefit to elderly people with disabilities, a combination of cash benefits and benefits in kind "which aim at making it possible for people requiring care to lead independent lives oriented towards their needs in spite of the restrictions they face". This is provided as a legally enforceable benefit, independent of income and assets. A benefits catalogue and quality standards for outpatient and inpatient sectors were set. The Law distinguished 7 different types of conditions that an elderly person may find him/herself in, calling for different care services. Level 1 concerns people who do not need more than

13. The share of "generics and original drugs priced at generic level" increased from $27 \%$ of all prescriptions in 2003 , to $46 \%$ in 2010 .

14. The demographic change will accelerate in the decade 2020-30: the baby-boom generation of the 1960s will then reach the age of 65 , and the share of the population above 65 will increase by 4.3 percentage points per year, attaining $24 \%$ in 2030 .

15. Standard assumptions help outline the impact of ageing on spending. Projections start from two alternative assumptions that they combine in varying proportions: $i$ ) a pure demographic hypothesis (based on stable age-specific disease rates, with longer life leading to longer periods of morbidity and costlier disease treatment), and a healthy ageing hypothesis (with the number of years spent in bad health staying constant and remaining concentrated in the latest years in life, with limited impacts on costs). Various combinations of these hypotheses permit to chart the bracket of spending paths. 
a relatively short visit per day; above level 3 people need 24 hours/stationary care; at levels 6 and 7 they need continuous day and night care. A monthly allowance is fixed for each level, from EUR 155 at level 1 to EUR 1650 at level $7 .^{16}$

22. Gauging the future distribution of dependency conditions is necessary to predict the future publicly funded care needs. Combinations of home-based, ambulatory, hospital and rehabilitation care will be needed. Their adequate combination will be important for both the quality and cost efficiency of care: a daily stay of an old-age person in a fully equipped hospital costs about EUR 800, while a stay in a more lightly equipped clinic declines to EUR 200. In more adapted settings, specially trained personnel may also provide better tailored services than high cost physicians. ${ }^{17}$

23. Projecting the care needs of dependant persons combines two alternative hypotheses (as with standard health spending projections): compression of dependence (i.e. chronic diseases come at higher ages, lifetime in dependence remaining constant) versus expansion of dependence (chronic diseases arising at constant age and lifetime in dependence increasing). Current nursing care need projections in Austria in co-operation with the European Commission include a pure demographic scenario (with constant dependency rates) and a social change scenario (with substitution of formal to informal care: $1 \%$ of those receiving informal care shifting to formal care each year). There are upward risks to these scenarios, as rising labour force participation by women could reduce available family care. Certain projections for nursing care places set for the year 2010 materialised several years earlier. The pace of shift from informal to formal care was identified by an early OECD analysis as a key upward risk on future spending projections (Oliveira Martins and de la Maisonneuve, 2006). ${ }^{18}$

24. Austria has however lower disability rates for its elderly population compared to Germany, Sweden, Denmark and the Netherlands. If this more favourable health status can be preserved and improved, it could exert a moderating impact on future care needs (Table 1).

16. Nine largely identical Länder acts followed. Two important agreements between the Federal Government and Länder shaped public commitments. A first agreement in 1993 recognised long-term care services as a responsibility of the nine Länder, subject to minimum service standards to be issued by the Länder themselves. A second agreement, in 2008, regulated public funding for "24-hour care", a specific type of support where helpers live in the dependent's home and are employed as private household staff. These persons were to be adequately trained. Some Länder adopted additional laws on specific types of care services, including for nursing homes.

17. The creation of "acute geriatric" departments in hospitals was a response to this need in the presence of excess capacity in acute care beds. Since 2000, hospitals have charged a flat rate per case for "geriatric medicine". They also pursue research, which can lead to new forms of treatment in age-related diseases such as Alzheimer, Parkinson and complex diabetes cases. Well designed palliative care is also a crucial and sensitive function, essential for the well-being of patients and families. There are innovative case management programmes in this area in certain Austrian hospitals, such as in the University Hospital of Graz.

18. As of 2007, Austria had an estimated 270000 dependant persons without counting those taken care of by their families. 63000 of these persons were taken care of in nursing homes, 122000 received daily visits, and 83000 received informal care - generally by self-employed immigrants organised by non-profit associations. 
Table 1. Disability rates of the elderly ${ }^{1}$

\begin{tabular}{lccccccccc}
\hline \multicolumn{1}{c}{ Age group } & \multicolumn{2}{c}{ G5-79 } & \multicolumn{2}{c}{$80-84$} & \multicolumn{2}{c}{$85-89$} & \multicolumn{2}{c}{$90+$} \\
& Gender & 12 & 20 & 28 & 40 & 33 & 46 & 41 & 53 \\
Austria & 19 & 19 & 38 & 43 & 40 & 48 & 44 & 58 \\
Germany & 18 & 12 & 29 & 40 & 34 & 48 & 41 & 54 \\
Sweden & 14 & 23 & 28 & 42 & 35 & 50 & 48 & 63 \\
Denmark & 10 & 18 & 31 & 34 & 37 & 43 & 47 & 55 \\
Netherlands & & & & & & & & &
\end{tabular}

1. As defined in the EU Share database: 'the percentage of people with the prevalence of ' $1+$ ' limitations with activities of daily living, among men and women over 50 years of age".

Source: European Commission (2009).

\section{Responsiveness to technological developments may create additional costs}

25. Giving the entire population equal access to state-of-the-art technologies is an important principle of the Austrian health system. It was reiterated in the context of the renewal of the constitutional agreement on health policies between the federal government and the Länder in 2008. It could put additional pressure on future public health expenditure, as a result of future technical innovations and change.

26. The balance between the costs and benefits of publicly funded health technologies - both treatments and pharmaceuticals - is in principle secured in Austria by applying Health Technology Assessment (HTA) (Wild et al 2010). HTA offers cost-benefit analyses for various treatments and services, and help policymakers decide on the coverage of the package. Still, HTA does not aim to cap public health spending, but to distinguish between cost-effective and cost-ineffective treatments. Austrian authorities intend to make more intensive use of HTA in the future but this will not necessarily reduce the impact of technological change on spending.

27. The utilization of HTA in pharmaceutical treatments gives an illustration of potentially limited impacts on volume of spending. HTA has been actively implemented in Austria for several years, with satisfactory results, and made the country highly receptive to efficient and high quality pharmaceutical innovations. A recent cross-country comparison on the diffusion of pharmaceutical innovations in Europe identified Austria as one of the most receptive European markets for pharmaceutical innovations (Richards, 2010). HTA appears to have contributed to a better-informed diffusion of new technologies. As long as adopting efficient state-of-the-art health technologies is a political goal, technological change should be expected to increase spending in the future.

\section{Health inflation entails additional pressures}

28. Recent international reviews of public health spending suggest that differences in countries' inflation rates in the health sector is a key factor of divergence of public health costs. Austria is a priori not favourably placed in this area. Cost and price increases in health are generally steeper than in other countries. If such inflation differentials persist, they are likely to put additional upward pressure on spending (Figure 9).

29. The 1997 OECD Economic Survey of Austria had already found that medical prices were 20\% above EU levels. The largest differentials relative to EU averages were found in the ambulatory care sector. The Survey observed that prices charged for the services of general practitioners, nurses and other practitioners, as well as for medical products and appliances, and for drugs and medicines were above EU average levels. The prices of specialist practitioners were found to be around the EU level. 
Figure 9. Pressures from health inflation
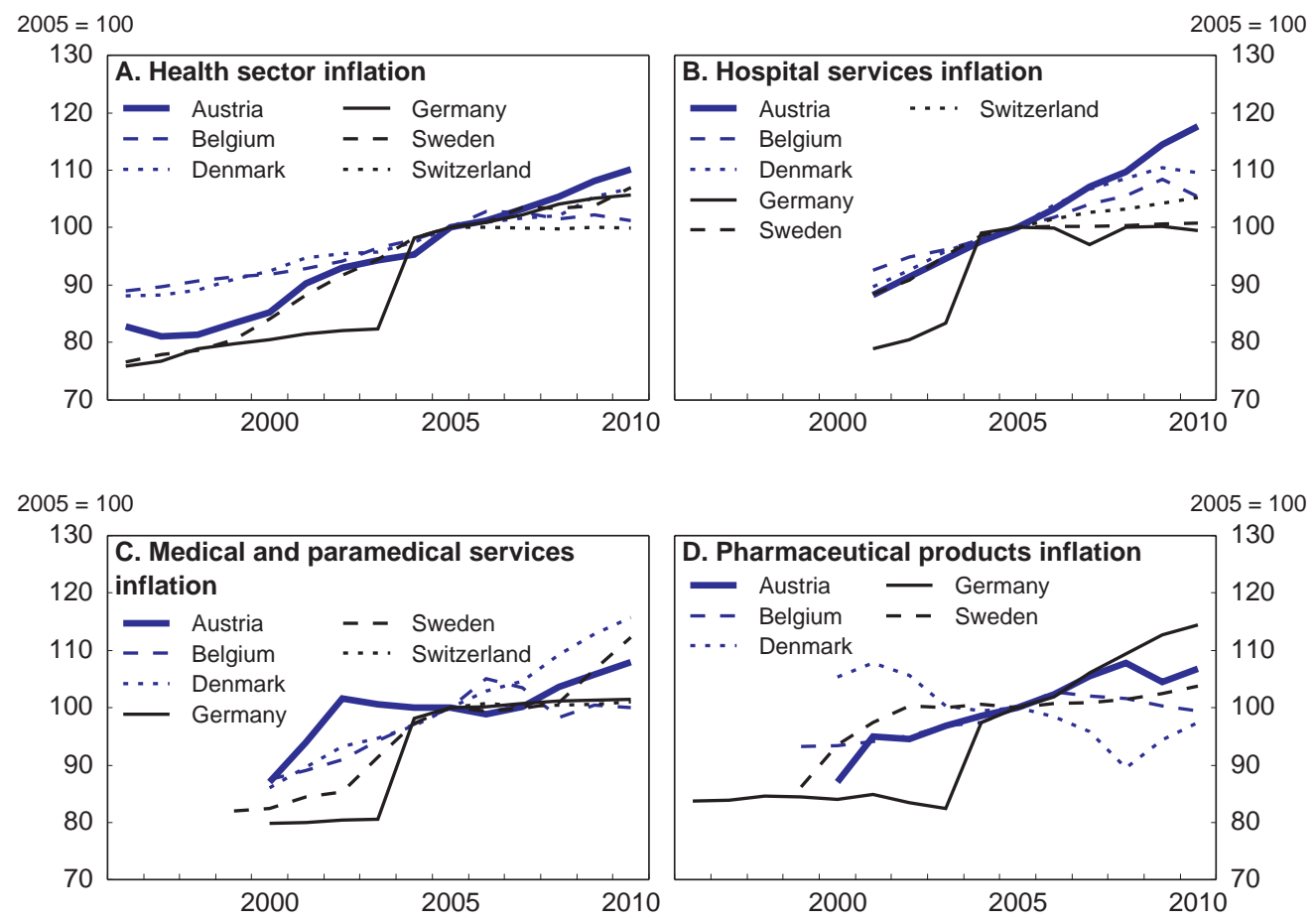

Source: Eurostat and OECD calculations.

30. Recent information confirms the persistence of these price pressures in Austria. For self-employed specialist physicians, the ratio of gross annual revenues to annual wages is now one of the highest in OECD, at about 4.8 times the average wage. For general practitioners, the ratio is also on the higher side, but closer to the international average at 2.9 times the average wage ${ }^{19}$ (OECD, 2009(a), see also Fujisawa and Lafortune, 2008).

31. These fee levels may partly result from the fragmented settlement of tariffs. For example, the Sickness Fund of the self-employed (SVA) recently suspended the contracting negotiations with the professional association of physicians, as they did not agree to lower tariffs to the level granted to regional Sickness Funds. An ad hoc arrangement was later found. More generally, higher fee levels for national branch funds increase doctors' income, while permitting to keep the fees paid by regional funds down. These differences call for more policy attention in the future.

19. Fee levels of independent physicians could be expected to interact with the wage levels of health professionals. Similar data is not available for salaried physicians and nurses, but wage premia for young hospital interns and nurses - who do not have sectoral representation through professional chambers appear to be low. Revenue levels of higher level hospital doctors ("managing doctors") is difficult to monitor because of their multiple remuneration elements, including fees for treating private patients (including private insurance patients) which may be dwarfing their official wages. Reported physician wages differ also across Länder. Annual labour cost per physician was EUR 103000 in Carinthia in 2009, against EUR 85000 in Tyrol, EUR 91000 in Vienna and EUR 94000 as a national average. 
32. To shed light on developments in health sector prices, Austria could participate in the new OECD project on Hospital Service Price Transparency. The objective of this exercise is "to explore if differences across countries in per capita health expenditures are due to more services being consumed in some countries, or whether they reflect differences in the price level of services". It is planned to generate detailed comparisons of a wide range of hospital fees through time (OECD, 2010d).

33. The Austrian authorities started to map more precisely the future public funding needs of the health and long-term care systems. A working group was created under the co-ordination of the Federal Health Agency and has started work. In addition to standard projections produced in the framework of European Commission's Working Group on Ageing - which are summarized below - detailed national projections could concentrate on the time horizon 2020-30 which is critical from the point of view of fiscal strategy. A fuller set of factors bearing on both ongoing spending and new financing needs can be investigated. This work may also draw on a new project in the context of OECD's Health Committee to evaluate alternative models of health spending projections by member countries.

\section{Current spending projections highlight risks}

34. The combined impact of the forces acting on public health spending start to be better understood at the international level. Internationally comparative medium-to-long term health spending projections start to be produced. Concerning Austria, three recent projections have shed light on the national health spending outlook. All three gave insights on the magnitude of looming pressures:

- A pioneering OECD project in 2006 helped identify the key factors bearing on public health spending across OECD countries. It introduced detailed and integrated methodologies for projecting long-term spending for health and long-term care (Oliveira Martins and de la Maisonneuve, 2006). The exercise focused on the horizon 2050 and did not offer projections for the more medium-term future 2020-30. Nonetheless, it suggested that, under alternative assumptions, the share of public health spending in GDP in Austria may increase by 0.6 to 3.8 percentage points of GDP between 2005-50.

- The European Commission produced, in 2009, a full set of health spending scenarios for member countries for the period 2007-60 (EC, 2009). It included for each country eight different scenarios, with different hypotheses on the evolution of demand, prices and costs. One methodological shortcoming of this exercise was that cost pressures from technological change were not directly taken into account. Yet, technological factors were introduced in separate special scenarios and permitted to charter a broad spectrum of possible future spending paths (Table 1). ${ }^{20}$

20. The Commission considered that the influence of technological progress on future costs was impossible to predict. Instead, it produced two additional technology scenarios on a stand-alone basis, with purely exogenous assumptions. One of these two scenarios will be referred to here as the "EU technology scenario". 
- The IMF has undertaken a similar study in 2010, following a comparable methodology (Cottarelli, C. et al., 2010). The exercise included technological and other cost pressures. It has compounded demographic effects with long-term spending trends in each country. The additional factors on top of demographic effects have been termed excess cost pressures, and have been estimated individually for each country. ${ }^{21}$

35. Table 2 presents the spectrum of spending trends arising from these exercises concerning Austria. The breadth of projections is large, ranging from an increase of 0.5 to 2 percentage points of GDP of further spending by 2020, and 0.9 to 5 percentage points of further spending by 2030. In the light of the specific upward pressures in the Austrian context, policymakers may wish to pay special attention to the "high public cost" scenarios which may be more fully capturing the forces in play.

Table 2. The spectrum of long-term health spending projections for Austria ${ }^{1}$

(as a \% of GDP)

\begin{tabular}{|c|c|c|c|c|c|c|c|c|}
\hline & 2007 & 2015 & 2020 & 2030 & 2040 & $\begin{array}{c}\text { Increase } \\
2007-20 \\
\text { (pp) }\end{array}$ & $\begin{array}{c}\text { Increase } \\
\text { 2007-30 } \\
\text { (pp) }\end{array}$ & $\begin{array}{c}\text { Increase } \\
2007-40 \\
\text { (pp) }\end{array}$ \\
\hline EC baseline & 6.5 & 6.8 & 7.0 & 7.4 & 7.8 & 0.5 & 0.9 & 1.3 \\
\hline EC "pure demographic" & 6.5 & 6.8 & 7.0 & 7.5 & 7.9 & 0.5 & 1.0 & 1.4 \\
\hline EC "technology"2 & 6.5 & 6.9 & 8.5 & 10.1 & 11.6 & 2.0 & 3.6 & 5.1 \\
\hline IMF baseline & 6.5 & 7.7 & 8.5 & 10.1 & 11.6 & 2.0 & 3.6 & 5.1 \\
\hline IMF optimistic & 6.5 & & & 8.0 & & & 1.5 & \\
\hline IMF pessimistic & 6.5 & & & 11.7 & & & 5.2 & \\
\hline $\begin{array}{l}\text { [p.m. EC spending baseline for } \\
\text { long-term care] }\end{array}$ & 1.3 & 1.3 & 1.4 & 1.7 & 2.0 & 0.1 & 0.4 & 0.7 \\
\hline
\end{tabular}

1. These projections concern only public health expenditure in a narrow sense, excluding public spending for long-term care.

2. Assuming the complete disappearance of the impact of technology by 2060 .

Source: EC, IMF, OECD.

36. In this environment, forging a shared view of the medium-term fiscal outlook of the health sector between health policymakers and economic policymakers would be useful. To this effect: $i$ ) the official health and long-term care spending projections (presently produced in the context of the European Commission) could be made more nationally visible; ii) the healthcare and long-term care components of scenarios be better integrated; iii) more detailed scenarios with the full range of hypotheses on the impact of technological change and future demands for new services could be developed; and iv) a medium-term (10-15 years) path for public health spending at general government level could be established. Also, in support of more immediate policies, the public health spending at general government level could be made a policy target associated with the multi-year budget framework which accompanies the annual budget law.

21. The IMF considered that these trends are rooted in the structural fundamentals of each country. Alternative assumptions on the persistence of the impact in the future underpinned one "optimistic" and one "pessimistic" scenario. 


\section{The efficiency of the system can be significantly improved, notably in the hospital sector}

37. Recent research helped to document that existing services deliver good health outcomes, but do not aim for a high degree of economic efficiency. In particular, hospitals absorb much wider resources than in other countries and appear to suffer efficiency shortcomings. Three streams of information help document this state of affairs: i) microeconomic reviews of efficiency in the hospital sector; ii) comparisons of resource utilisation in regional health systems; and iii) aggregate assessments of national health system efficiencies in international comparison.

\section{Hospitals' microeconomic efficiency can be improved}

38. Hospital efficiency analyses have been well developed in Austria, on the basis of Data Envelopment Analysis (DEA) techniques. A 2005 study uncovered an average level of DEA inefficiency of $20 \%$ in a sample of hospitals (i.e. an average distance of $20 \%$ to the national efficiency frontier), suggesting that up to one fifth of hospital costs could be saved (Hofmarcher et al., 2005). Additional recent research confirmed the existence of large efficiency gaps within the sector, but traced them more directly to the ownership structure of hospitals (Czypionka et al., 2008). As also shown in the 2005 study, non-profit institutions owned by religious congregations appeared to operate at first sight more efficiently than public hospitals. Within the public sector, hospitals owned by the municipalities seemed to be more efficient than those belonging to the Länder. ${ }^{22}$ The study reiterated, like the previous one, that the variation of efficiency within ownership groups is larger than between groups. This indicates that there is room for large productivity gains in all categories of hospitals.

39. There are however two caveats to these findings. First, a difference between Länder-owned hospitals and non-profit peers is that Länder hospitals are legally required to provide a high level of outpatient care activity (not required from private peers) which increases costs. Second, these measurements do not control for the quality of care and for the complexity of treatments. For example, the poor performance of accident hospitals may be partly due to the type of services that they provide (rehabilitation is a long and labour and capital intensive process). These caveats do however not rebuff the general conclusion on the presence of large efficiency reserves.

40. Insufficient technical specialization between hospitals is also a major present issue. Each Land has developed its own hospital system and this has made the specialization of hospitals difficult. Länder hospitals remain polyvalent and patients are not encouraged to travel to specialist institutions remote from living places - except in critical cases. It was simulated, for example in the area of breast cancer surgery, that 35 sites in Austria should suffice to perform this treatment at the required degree of frequency, while around 110 sites currently offer this service. Lack of specialization undermines both the efficiency and quality of services.

\section{Resource utilisation can be enhanced in several Länder}

41. The OECD methodology utilised for the international comparisons of national health system efficiencies (section below) has been duplicated, for the purposes of this Survey, to compare economic efficiency levels in the nine Austrian Länder. The estimation suggests that the variation of efficiency levels is very high (Figure 10). Certain Länder achieve consistently better outcomes than others and, symmetrically, underperformers spend considerably more resources for given health outcomes. The exercise is subject to methodological caveats (notably because of cross-Länder movements of patients, in particular towards Vienna, which undermines Vienna's estimated efficiency) but suggests that the potential for additional productivity gains is large.

22. In recent years, hospitals owned by the municipalities were increasingly taken over by the Länder. 
ECO/WKP(2011)64

\section{Figure 10. Comparisons between Länder suggest that there is large room for efficiency gains}
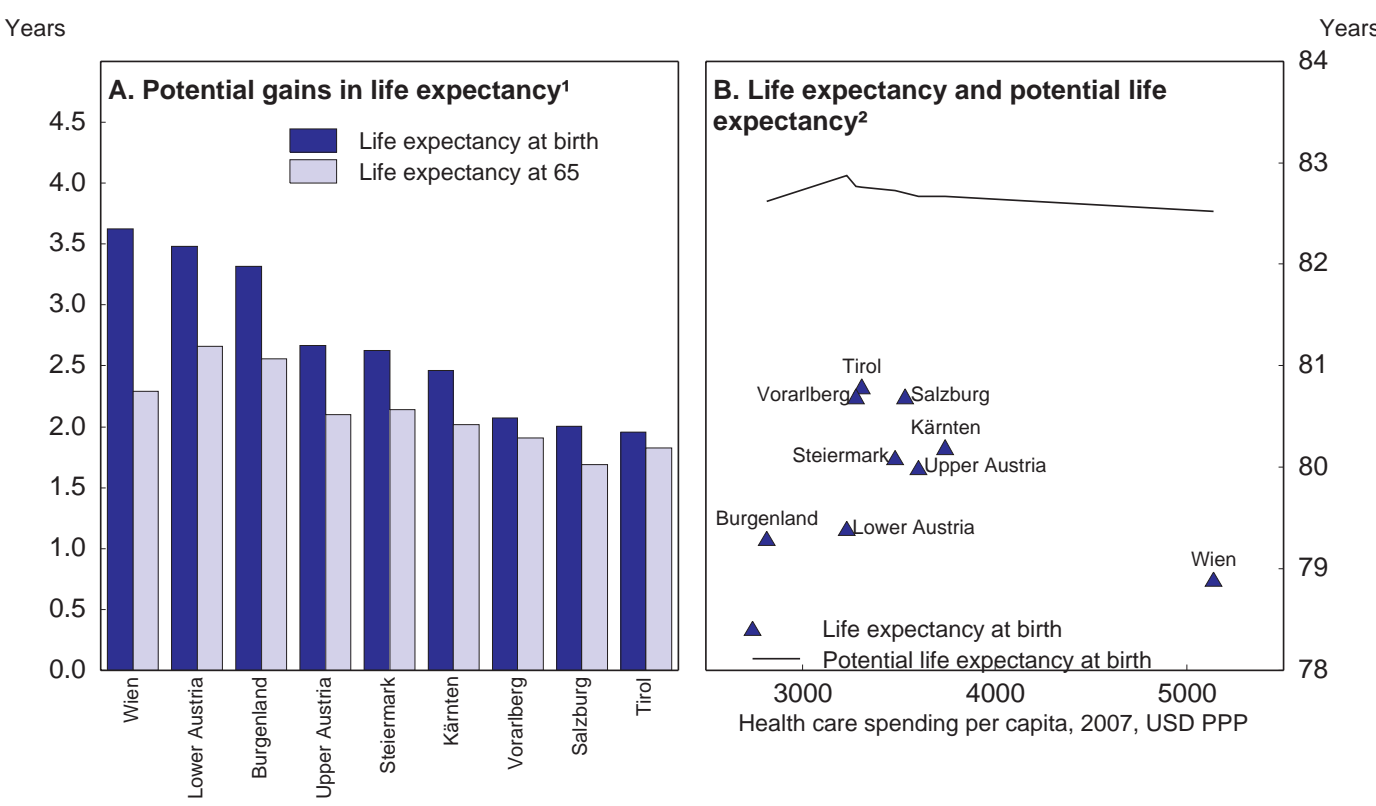

1. DEA efficiency calculations were performed with two inputs: health care spending per capita and a variable which is a composite indicator of the socio-economic environment (GDP per capita, educational attainment) and lifestyle factors (nitrogen oxide emissions, consumption of fruit and vegetables, lagged consumption of alcohol and tobacco - 1990 data).

2. Potential life expectancy represents the life expectancy level if the potential gains in life expectancy as obtained by DEA calculations were realised keeping the same amount of health care spending. It takes into account the experience of other OECD countries. The graph is a two-dimensional representation of a multi-dimensional computation (distances from efficiency frontier are not necessarily readable on a plan) while in this instance it does show the estimated potential for life year gains.

Source: OECD calculations based on OECD Health Data 2010.

42. More detailed investigations comparing spending and cost structures across Länder confirm this finding. Austria's Court of Auditors undertook several such studies. In light of these findings recent data suggest that important differences persist through time. For example, cost per activity point in "basic profile" hospitals in 2009 (calculated in detail for the DRG system, Box 4 below) was EUR 1.25 in Lower Austria and EUR 0.85 in Tyrol, against a national average of EUR 1.12. ${ }^{23}$ Similar differences were found in other hospital categories. Hospitals in Tyrol, Vorarlberg and Salzburg appeared more efficient than those in Lower and Upper Austria. Other work by the Court of Auditors revealed similar inter-Länder differences (Figure 11).

23. 132 "general public" hospitals were classified into five groups: "basic profile" hospitals (64), "extended basic profile" hospitals (31), "high profile" hospitals (5), "university hospitals" (3) and "specialty hospitals" (30). 
Figure 11. Inter-Länder differences in health system costs

(Standardised deviations from national level)

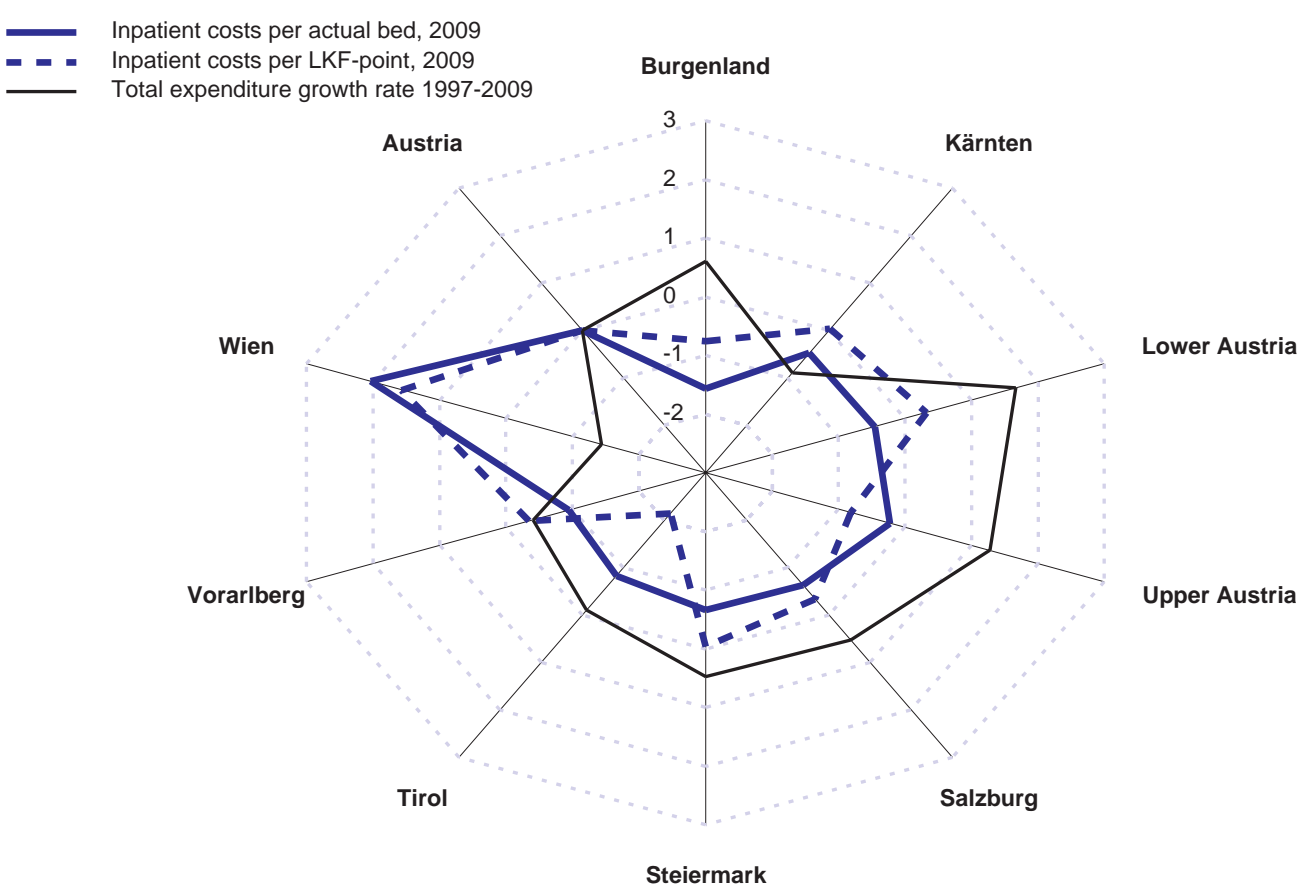

Source: Ministry of Health and Institute for Advances Studies, HealthEcon 2011.

\section{The aggregate efficiency of the system falls short of best practices}

43. Recently, a large-scale OECD study has applied Data Envelopment Analysis to measure the economic efficiency of national health systems in 30 countries. It compared the average population health outcomes attained in each country (proxied by average life expectancy, which is an imperfect proxy but is reasonably well correlated with other indicators) with a set of inputs (such as health care resources per capita measured in monetary and physical terms, socio-economic inputs including education and pollution, and life-style factors including diet), and established how well each national system transforms these inputs into health status. Countries generating the highest life expectancy at given input levels, and those reaching given life expectancies at the lowest input costs, are said to form the international efficiency frontier (OECD, 2010a).

44. Results suggest that if Austria had used its current level of resources with the same efficiency as the best performing countries, it could improve the life expectancy of its population by two years and a half, roughly speaking half of the progress achieved in the past 40 years. They also implied, symmetrically, that if Austria's system was operating at the frontier level of efficiency, spending could be reduced by 2 percentage points of GDP or one fourth of the current public expenditure for healthcare. With this level of estimated performance, Austria takes place in the lower half of the 30 countries - among those which have more life years to gain than average. These estimates confirm the existence of a large reserve for efficiency gains (Figure 12). 
Figure 12. A comprehensive international comparison reveals room for efficiency gains
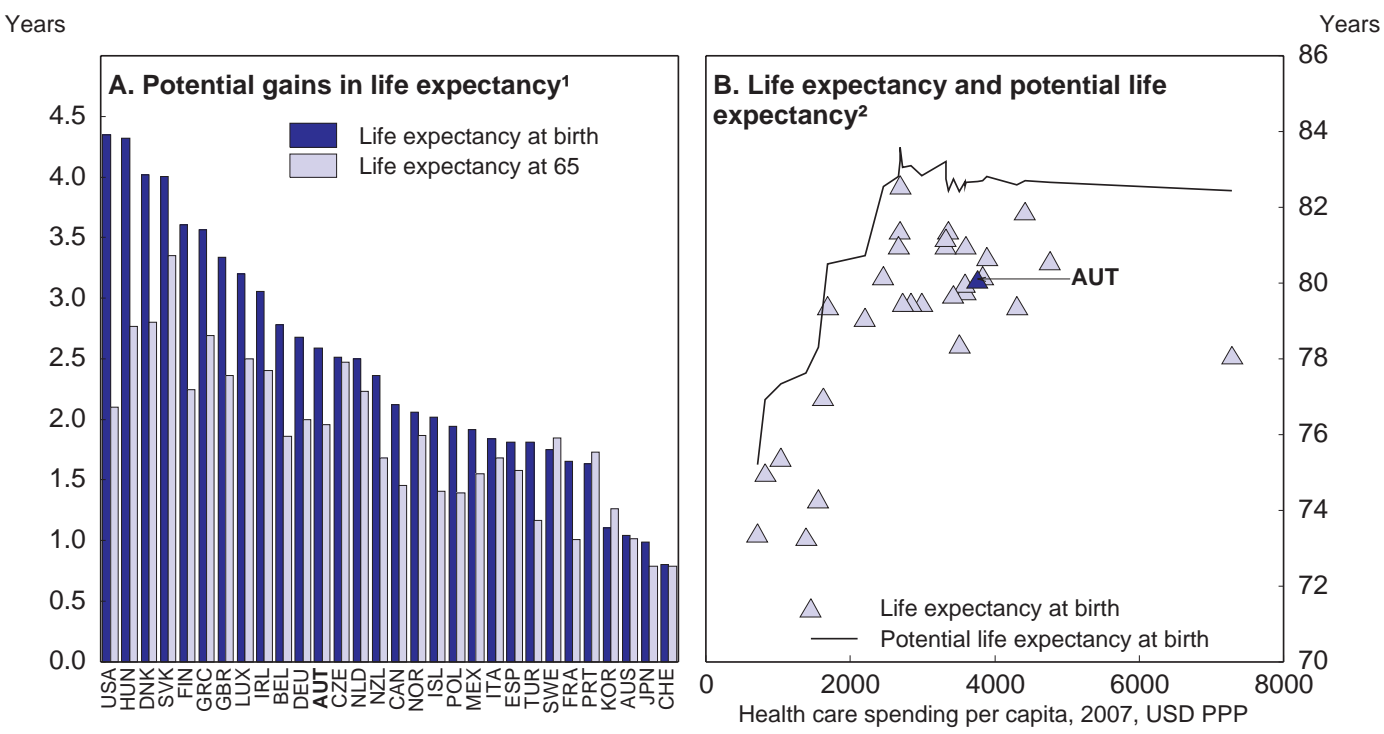

1. DEA efficiency calculations were performed with two inputs: health care spending per capita and a variable which is a composite indicator of the socio-economic environment (GDP per capita, educational attainment) and lifestyle factors (nitrogen oxide emissions, consumption of fruit and vegetables, lagged consumption of alcohol and tobacco - 1990 data).

2. Potential life expectancy represents the life expectancy level if the potential gains in life expectancy as obtained by DEA calculations were realised keeping the same amount of health care spending. See also footnote 2 of Figure 10.

Source: OECD (2010), Health Care Systems: Efficiency and Policy Settings.

45. A spending area where there is some recent, tentative and intriguing domestic research is the utilization of pharmaceuticals. A 2009 study by the University of Salzburg ${ }^{24}$ suggested that $36 \%$ of the pharmaceuticals used in Austria by old-age persons appear to be dispensable, 30\% of pharmaceuticals appear to have doubtful clinical relevance, and $23 \%$ are incorrectly dosed. The study observed that total pharmaceutical consumption increased by $90 \%$ over the past decade. Austria is indeed one of the OECD countries where pharmaceutical spending has increased most sharply (Figure 5 above).

\section{Key shortcomings have started to be addressed but further action is needed}

46. Addressing and reducing these efficiency shortcomings is now an agreed goal of Austrian policymakers. Successive vintages of health reform initiatives since 1997 aimed at lifting up the efficiency of the system (Hofmarcher et al., 2006). Action in four areas was prioritized: asserting stronger federal government influence on long-term capacity development (improving allocative efficiency); introducing payment systems emulating market disciplines and helping catch-up with productivity benchmarks (technical efficiency); upgrading outputs by improving quality (increasing quality-adjusted output); and accelerating transition to integrated care via a better balanced combination of preventive, outpatient and inpatient services. Good results start to be obtained from these initiatives, but continuing action is needed to foster actual structural change.

24. Quoted by K. Langbein, 2009. 


\section{Capacity planning should be consolidated}

47. Since 2005, the Ministry of Health has reactivated efforts to direct capacity building in the national health system, in both inpatient and outpatient sectors. A new "National Capacity Plan" (Österreichischer Strukturplan Gesundheit, ÖSG) is intended as a central strategic instrument. Each Land is required by law to produce a regional plan in co-operation with its regional Sickness Fund (Regionaler Strukturplan Gesundheit, RSG), compatible with the national plan and targeted to put it in application. "Land Health Funds" and "Land Health Platforms" are created, consolidating resources from various federal and regional public sources to promote the rationalisation of regional service supply structures.

48. ÖSG follows from an earlier Österreichicher Krankenanstaltenplan (ÖKAP, Austrian Plan on Hospitals), elaborated in consultation with the Länder, and dating from 1997. The Länder had had a strong influence on the elaboration of ÖKAP, and ÖKAP had not entailed any significant departure from existing and locally planned capacities. In contrast, ÖSG aimed at remaining less bound by existing capacities and asserted more influence on the actual development of capacities. Its first version was finalized in 2006, and its 2010 version outlined, on the basis of benchmarks by the National Planning and Research Institute - Gesundheit Österreich GmbH - inpatient and outpatient service needs for 2015 and 2020. The plan aims at reducing the gap between needs and capacity, and to improve both efficiency and resource allocation.

49. However, early experience with ÖSG has not been very conclusive, despite the amount of expectations and resources invested in the effort (Hofmarcher 2010a). Concerning the steering of hospital capacity, Länder's continuing control of RSGs did not permit any significant deviations from existing and locally planned capacities, even if certain Länder tried to comply more with ÖSG objectives than others. Sickness Funds' "contracted physician networks" could also not be taken under the umbrella of the national plan: they continued to be shaped by negotiations between physicians' regional chambers and regional Sickness Funds, with limited connection with ÖSG so far. The goals of the plan have also been weakened by the concept of an "adjustment coefficient" in implementation, advocated by several Länder, implying that targets would be abided by only in some proportion ("the coefficient", for example by $25 \%$ below or above national goals). Sanctions legally available to discipline non-complying Länder could not be put in practice.

50. Against this background, a new strategic document ${ }^{25}$ presented by the Federation of Sickness Funds in November 2010 judged that the capacity targets of ÖSG were not being guided by appropriate public health goals (Hauptverband, 2010). Hauptverband suggested that all key stakeholders (federal government, Länder and Sickness Funds) should develop together more ambitious targets. These targets should capture true service needs, including in the areas of public health and prevention. One illustrative suggestion was to decrease the number of projected foot amputations for patients with diabetes, thanks to much more effective preventive policies, rather than extrapolating historical trends. Hauptverband also proposed that planning should be done for broader areas than individual Länder, arguing that the average population size of 1 million per Land falls short of minimum scale for effective planning. It suggested that planning objectives should be made compulsory and compliance be monitored independently. These suggestions are predicated on far-reaching changes in the institutional environment.

\section{Payment mechanisms should be refined}

51. New performance-based payment mechanisms started to be introduced, designed to encourage service suppliers to catch-up with national productivity benchmarks. This was first introduced for the payment of hospital services, since 1997 and in successive steps, on the basis of a vast national co-operative project (Box 4). Austria was among the first OECD countries do adopt such a scheme (Erlandsen, E., 2007).

25 .

Masterplan Gesundheit, 2010. 


\section{Box 4. The Austrian DRG system: promises and setbacks}

Since $1997,60 \%$ of the operating costs of hospitals are funded according to the treatments that they provide. The units of calculation are points allocated to each type of treatment, on the basis of diagnosis related groups (DRG). 982 different types of treatment are distinguished, and the number of points for each treatment is determined on the basis of around 500000 inpatient stays in 20 reference hospitals. The system therefore pays each treatment according to a national cost benchmark, irrespective of the hospital's own costs. It therefore emulates a competitive pricing mechanism, giving hospitals incentives to converge with and overcome national productivity norms.

"Point values" are set retrospectively at the level of each Land, at the end of each accounting period, by dividing the ex ante hospital budget of the Land by the number of ex post points "gained" by the Land's hospitals. The total budget for hospitals remains therefore fixed and is not affected by the total volume of points (services) provided. Upon inception, this feature was greeted by international health economists as a promising innovation for controlling hospital expenditure, while also preserving market-driven flexibility in the allocation of hospital budgets. It is available today only in a few countries operating DRG systems. ${ }^{26}$

The system includes also some additional discretionary options for each Land:

- In the so-called "Uniform Core Area" of the payment procedure, the points awarded for each type of treatment are based on national benchmarks.

- The second area of the payment procedure (the "Land Control Area") can be modified by each Land. It enables the Land to top up the national cost benchmark for each type of treatment with some preferred level of staffing, equipment, and other quality criteria.

Hospitals claim that the DRG system does not adequately reflect their outlays for outpatient services, while many of these services can be more efficiently provided by hospitals rather than independent physicians.

The fixed hospital budget of each Land is jointly financed by the federal government, Land government and Sickness Funds. It is consolidated in a "Land Health Fund" uniquely dedicated to DRG payments, and has an autonomous management structure. The Fund finances about $60 \%$ of the total operating costs of hospitals in the Land. The Land Health Fund was initially intended to fund $100 \%$ of the operating costs of hospitals, but was subsequently scaled down.

Actual experience with the DRG system in the first decade of implementation has been somewhat mixed. Despite important benefits in a range of areas, the system has not yet fulfilled its full promises:

- The expected efficiency gains from the new payment mechanism were initially achieved. The average length of stay in hospitals declined drastically, below OECD averages.

- Yet, hospitals tried to maintain their revenues by maximizing their number of points. The number of hospital admissions accelerated above trend.

- Two loopholes with respect to the basic philosophy of the DRG system continues to exist: payments under Land Control Areas above national standards, and financing made available beyond the DRG system: about $40 \%$ of the current costs of hospitals continue to be financed outside the system.

- Patients seeking outpatient care are frequently admitted for inpatient care, as hospitals have no other "medical home" for these types of services. This contributes to the expansion of hospital admissions.

- In sum, since the introduction of the DRG system the transparency of hospital activities has considerably improved for the authorities - the wealth of data arising from the DRG system has not been made public but hospital costs have only slightly decelerated.

The DRG system continues to be refined on the basis of experience. The catalogue of nearly 1000 cases is periodically revisited, and reference cost levels are updated. Still, as long as the built-in "loopholes" in the system

26. Beside Austria, Germany and certain Swedish regions appear to operate a form of a "cap and divide" technique in the valuation and funding of DRG points. See HOPE, 2006. 
persist, the expected benefits may be difficult to achieve.

\section{The ancillary issue of private insurance funding for hospitals}

In addition to the DRG system which governs the public funding of hospitals, private insurers reimburse these institutions for offering special amenities to privately insured people. This supplements the income of the hospital companies, managing doctors and their teams.

This procedure entails however one distortion: Länder's hospital laws stipulate that in publicly funded hospitals, the number of beds for privately insured people should not exceed $25 \%$ of the bed capacity available for people who are covered only by Sickness Funds. This creates an incentive to keep bed capacity high, as bed cuts in "common wards" implies cutting back beds for "Sonderklasse" patients.

In an assessment of the issue in 2006, the Federal Audit Office recommended that funding from private insurers be made transparent, and that all stakeholders should receive an "appropriate" share of these fees. The Office recommended that a unified fee be charged to private insurers for each treatment, covering both the doctors' supplemental income and a charge for using hospital infrastructure.

The policy issue is admittedly complex. Any capping of private insurance contributions could have unintended consequences: First, public wage expenses for managing doctors may need to increase if they are unable to supplement their income. Second, giving doctors the option to supplement incomes with private insurance fees may be creating positive side-effects, because higher quality services are made available not only to privately insured patients, but also to public insurance patients.

52. The authorities are considering extending the principles of the DRG system outside the hospital sector, toward outpatient care. If national cost benchmarks could be set for treatments in the outpatient sector, and fees were established on that basis, benefits similar to the DRG system's may be anticipated. Ambulatory care provided for similar cases by independent physicians, the outpatient wards of hospitals and - gradually - polyvalent group practices could then be paid similar fees, and the most efficient care platforms can gain an edge. Part of the treatments could then shift to care settings where they are provided more efficiently and at a standard level of quality. Transiting to such a payment system in outpatient care would be a long process (the DRG system took several years to design and implement), entailing detailed case classification, quality normalization and cost benchmarking tasks. The authorities are nonetheless willing to engage in this direction.

53. The payment system for pharmaceuticals was also considerably modified. Drugs are classified into three categories, with different degrees of automaticity in their reimbursement - along international best practice. "Green box" medicines are readily reimbursed, "Yellow box" ones require authorization by social insurance chief physicians, and the "Red box" contains medicines for which a reimbursement policy is not established (Leopold et al, 2008). The latter group of medicines are submitted to health technology assessment (HTA) to evaluate their cost-benefit balances, and are authorized or not on that basis. If this new payment mechanism is backed with additional measures in favour of generics (which still have a relatively limited share in the Austrian pharmaceuticals market) ${ }^{27}$ it could deliver important savings.

54. Policymakers should continue to move to payment mechanisms fostering productivity gains: by financing services according to quality and cost criteria; by relying more on competition; and, when services are provided by national or local monopolies, notably when negotiating with medical chambers, by using as much as possible national cost benchmarks and yardstick competition.

27. See above footnote 13 . 


\section{Service quality should be better monitored}

55. The quality of health services matters for the efficiency of the health system. It determines patients' health status, reduces need for follow-up care, and minimizes hospital re-admissions. There is a widely shared belief that health services are of a high quality in Austria, and that this quality is homogenous across the territory. Several national health experts observe however that this assertion is not backed by objective criteria or indicators. The Austrian system's operating without standard quality indicators is indeed one of its distinct characteristics. In a recent review Austria came out as being particularly poorly endowed with formal quality indicators (Paris et al., 2010).

56. Some internationally comparable indicators are nonetheless available to broadly evaluate quality outcomes (OECD, 2009a). The full range of indicators is not available for Austria (notably survival rates in certain health conditions such as cancers). Still, those that are available provide a preliminary comparative picture (Figure 13). They confirm that Austria succeeded in reducing mortality rates from certain frequent diseases clearly below OECD averages, and below averages in other high income countries such as Sweden, Denmark and the Netherlands. ${ }^{28}$ In other areas, outcomes are similar to comparable countries. ${ }^{29}$

Figure 13. Some available indicators of quality of care

$$
\text { Amenable mortality rates per } 100000 \text { population }
$$

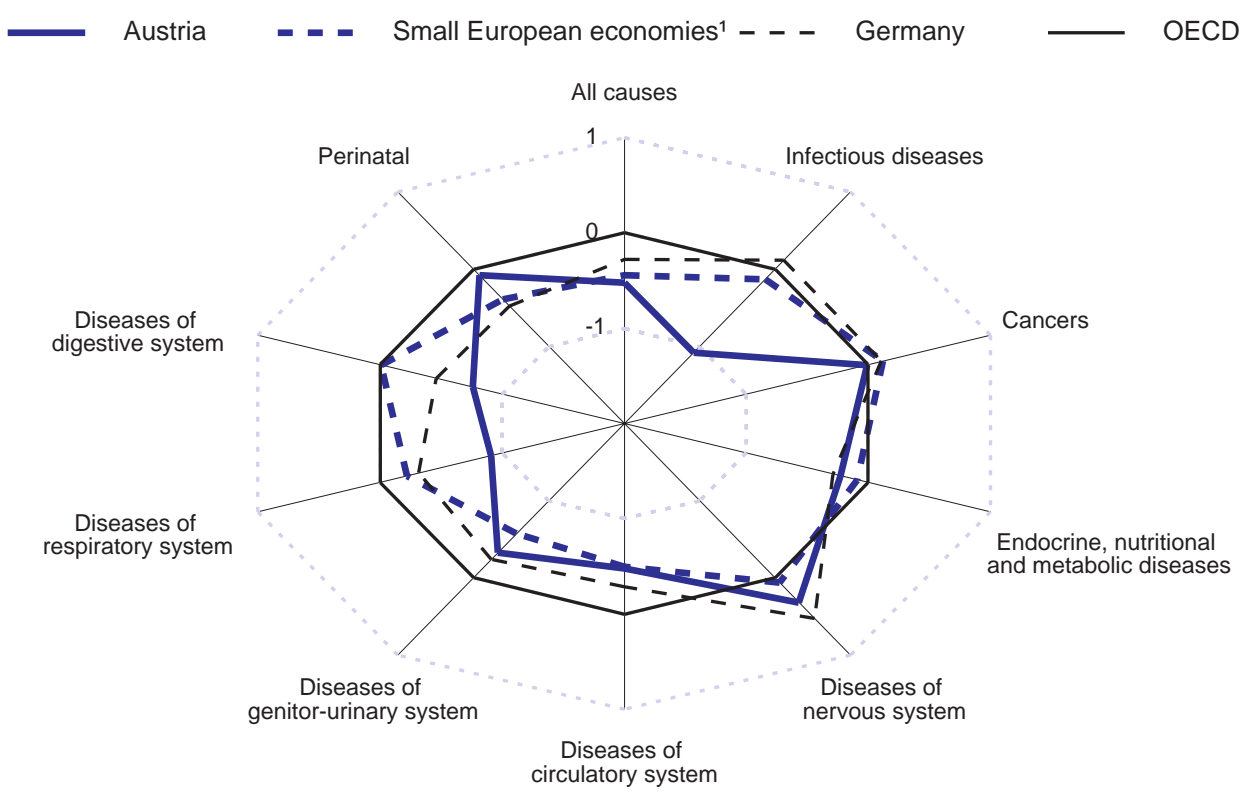

Note: Amenable mortality is defined as those deaths that were potentially preventable by timely and effective medical care. Data points outside the average circle indicate that the level of the variable for the group or the country under scrutiny is higher than for the average OECD country. Data represent the deviation from the OECD average and are expressed in number of standard deviations.

1. Arithmetic average of other small European high income economies: Denmark, the Netherlands and Sweden.

Source: OECD estimates based on Nolte and McKee (2008), "Measuring the Health of Nations: Updating an Earlier Analysis", Health Affairs, January/February 2008.

28. Notably from infectious diseases, and from the diseases of the digestive and respiratory system.

29. Such as the diseases of the circulatory and genitor-urinary systems, and cancers. 
57. More specific indicators are also used to compare the quality of health services, such as "avoidable hospital admission" rates for specific diseases, and participation rates in public health programmes (OECD, 2011). These indicators suggest that there is room for improvement in these specific fields (Figure 14). The Austrian system is for example characterized by a comparatively limited outreach of certain important vaccination programmes. ${ }^{30}$ As a result, the incidence of a serious disease such as hepatitis B is higher than in comparable countries.

Figure 14. Other more specific indicators suggest room for improvements
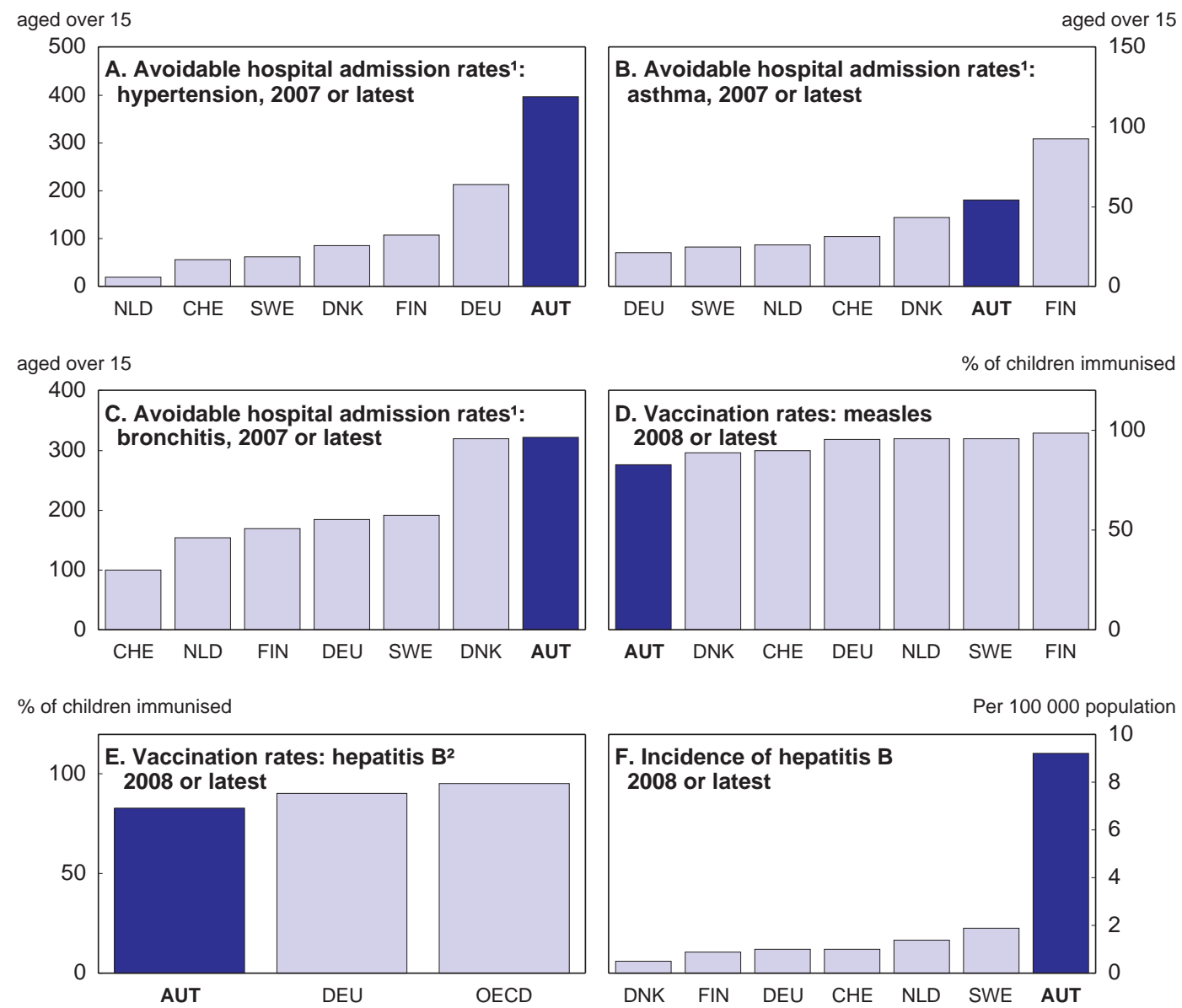

1. Defined as the number of hospital admissions of people aged 15 years and over per 100000 population in that age group per year. The assumption behind this indicator is that, given today's treatment options to prevent acute exacerbations, no hospital admission should be necessary.

2. OECD average only includes countries with required or routine immunisation.

Source: OECD Health Data 2010 and OECD Health at a Glance 2009.

58. The authorities are aware of the need to reinforce the monitoring of quality. An "Austrian Quality Strategy" (Österreichische Qualitätsstrategie) was introduced by the Health Reform Act of 2005, which included a comprehensive federal quality strategy. A Federal Institute for Quality in the Health Care

30. There are some concerns however that available vaccination data in the Austrian context could be incomplete and may underestimate actual vaccination rates. 
System (Bundesinstitut für Qualität im Gesundheitwesen) was created, ${ }^{31}$ inspired by the system of quality indicators successfully put in place in Germany. ${ }^{32}$ Quality reports were to be written on all sectors and professions according to uniform methods, for example in the area of antibiotics use, the use of blood components, microbiological diagnoses etc. However, implementation regulations could not yet be put in place, and quality reporting as requested by the law has not yet come through.

59. The Ministry of Health re-asserted the need to develop a quality monitoring system in the context of the saving package of 2009. A Critical Incident Reporting System was introduced in November 2009, as a mutual information tool between providers, on adverse events anonymously reported on a web-based system. It is expected to improve patient safety (Hofmarcher, 2009). Partners such as the Medical Chamber and Sickness Funds were also asked to formulate measurable quality objectives, with a view to produce quality reports. However, this wider multi-stakeholder co-operation has not yet made progress.

60. In early 2011, the Minister of Health reiterated the importance of quality reporting and proposed a more binding federal quality law applicable to all services provided in the territory. A nationwide quality reporting system ("Health-Q-Reporting" programme) is projected to start in 2011. In this effort, Austria could draw on a project starting in OECD's Health Committee to evaluate Member countries' quality policies.

\section{Transition to integrated care should be accelerated}

61. Austrian system's excessive bias toward hospital services affects all dimensions of efficiency. This structure makes it difficult to reduce costs, and improve the quality of services through better complementarity between public health, prevention, outpatient, inpatient and rehabilitation programmes. Transition to such integrated services is considered today as an international best practice, as recently reiterated by the 2010 OECD Ministerial Conference on Health Policies (Box 5).

\section{Box 5. Transition to integrated care}

Transition to "integrated care" is recognized as a common policy priority across OECD countries (Borowitz et al., 2010). It emphasizes patient-centred care, and coordination of care between primary and secondary services. It may involve co-operation between specialists within medical teams, and between health and social service sectors (Leutz, 1999). Transition to such integrated services becomes particularly necessary in response to the changing needs of an ageing society, the expansion of chronic diseases, and multi-morbidity (Stein, 2009).

There are numerous models of integrated care being implemented in various countries: disease management programmes, selective integrated care contracts, integrated care groups and medical home models. These models are seen as means of promoting efficiency, and better patient outcomes, as well as addressing the problems of fragmented service delivery. There is an increasing need for new service design, promoting collaboration and co-operation between the different components of the health system.

31. Under the auspices of Gesundheit Österreich GmbH, the research arm of the Ministry of Health.

32. Germany also initially lacked a satisfactory health service quality monitoring system. An assertive transparency quality policy was put in place in the 2000s, with the creation of the German Institute of Health Quality Standards. The set of indicators developed and monitored by this Institute are considered today as international benchmarks. 
62. In Austria, transition to integrated care is slow. As there is no 'gate keeping' function in the system, General Practitioners hardly act as care managers in a consistent way. Different services have firewalls between them, such as boundaries between preventive, generalist, specialist, inpatient and rehabilitation services. This segmentation makes Austria's transition to integrated care more difficult, and generates efficiency and quality losses. There is some concern for example that the quality of the important national check-up scheme may have been seriously undermined by the absence of an integrated approach, and capture by special interests (Annex A3).

63. Federal authorities and local health experts share this diagnosis. Many recent policy initiatives in Austria aimed at fostering new forms of integrated care. Promising results were obtained by certain of these efforts, but they have not altered the inpatient focus of the system. Austria's experience suggests that more systematic institutional changes are necessary to disseminate the new approach. Five recent experiences are worth reviewing:

- The creation of "Land reform pools". In 2005, a new instrument was created in each Land to stimulate greater patient flow between sectors. The Federal Health Agency was asked to draw up guidelines for co-operation between inpatient care, day care and outpatient activities. These guidelines were meant to give practical guidance to the reform pools in selecting new types of services to be funded. One per cent of federal health spending was re-directed immediately to these pools, and this share was to be increased to $2 \%$ by 2008 .

After a slow take-off in 2006, reform pool projects expanded in 2007, and then slowed again in 2008. The complex governance structure of programmes, which included all local stakeholders, limited the innovativeness of projects, and interest declined. An evaluation in 2009 suggested that less than $20 \%$ of the resources available in reform pools were actually used (Czypionka and Röhrling, 2009).

- Disease Management Programmes (DMPs). These programmes have been the main gate of entry of integrated care in Austria (OECD, 2010b). The idea was inspired by North American innovations, and was adapted to Austria by embedding the treatment of patients with chronic diseases into primary care. ${ }^{33}$ This implies making additional payments to General Practitioners to co-ordinate care. Traditionally, GPs have had little incentives to prioritise prevention, or to co-ordinate care. In DMPs, they receive direct financial incentives, and clinical guidelines and technical support. This innovation was introduced for Type 2 diabetes in 2007, and has developed rapidly. As of 2010, more than 400 physicians were participating. According to an early evaluation (effected in Salzburg, in a large randomized study) the programme has significantly reduced the average glucose concentration of participants, improved hypertension, and increased the uptake of preventive measures. The study will continue to follow patients and will provide information on the long-term effects of disease management.

- The government tried recently to foster "group practices of physicians" as an avenue for integrated care supply. Group practices were traditionally rare in Austria, and were confined to specific areas such as physical rehabilitation. In 2009 the government tried to legislate a new legal form for group practices ("Ärzte GmbH") "to better balance utilization and integration of inpatient and outpatient care". However, after strong opposition by interest groups, the proposal was amended in restrictive directions. "Ärzte GmbH" can now be created in single specialties (such as "radiology", "internal medicine", "general surgery"). Only physicians can be shareholders, and cannot employ salaried doctors (Hofmarcher et al., 2010b).

33. Austrian and German Disease Management Programmes have a similar design. They differ from the original US innovation which embedded this function in integrated service organisations. 
- Pilot experiments could play a pioneering role in exposing the benefits of integration. Most recently, the Sickness Fund of the self-employed (SVA) started an integration experiment. ${ }^{34}$ In agreement with its network of physicians, it launched new coaching and prevention services, inspired by the traditional role of a family doctor. Fund members are not obliged to use these services, but receive a financial incentive if they do so. SVA emphasized that the high education level of its membership is an asset in implementing this "revolutionary new orientation". 2011 will be the first year of implementation of this package.

- Active, well-informed patients can also be a driving force in promoting integrated care. In early 2010, the Ministry of Health launched the "Austria health portal", to help the population to become better informed users of services. The portal offers easy to retrieve information on prevention, diagnosis and treatment options. On the basis of individual tests, specific guidance can be provided. The portal includes also information on the safety records of various drugs. Early user rating of this service has been very encouraging. The authorities announce that in the final phase of its development, the entire population will be given access to their own Electronic Health Records, possibly in relation with preventive applications. Austria's expertise and lead in e-government (OECD, 2009e) reinforce the project of putting in place an individual electronic health record infrastructure for the entire population, the ELGA system. ELGA offers the potential of providing the physical infrastructure of future integrated care innovations (Annex A2).

64. Finally, an idea which has been aired in government circles in recent years, without being put in application, is to give the outpatient wards of hospitals a leading role in promoting integrated care. The 2007 government programme mentioned this possibility. These wards, which are densely available across the territory and enjoy the confidence of the population, could offer a platform for integrating prevention, gate-keeping and care management services. However, they lack their own management and budget structures at this point, and cannot develop into autonomous integrated service entities (they continue to be financed to a large extent from the inpatient budgets of hospitals). ${ }^{35}$

65. The experience of other OECD countries making good progress with integrated care suggests that both strategic guidance at the policy level, and an open and enabling contracting environment at the microeconomic level are important for transition to integrated care. Financial incentives to innovative practices also play a role, by facilitating innovation and demonstration (Box 6).

\section{Box 6. Open contracting and payment for integrated care: lessons from other OECD countries}

In the area of integrated care, Denmark, Germany and the Netherlands are front-runners. Administrative reforms in Denmark have shifted the focus towards more patient-centred care and a series of health reforms in Germany has paved the way for improved coordination of care. The Netherlands has been successful at implementing new chronic integrated care programmes. There are lessons that Austria could draw from these experiences.

34. The Social Security Institution for Trade and Industry (SVA) is the Sickness Fund of entrepreneurs and liberal professions. It has about 700000 members, composed of 340000 professionally active, 230000 dependant family members and 130000 pensioners.

35. Outpatient clinics could create competition for physicians in private practice, and have in the past stirred opposition from professional organisations. The so-called "outpatient clinic debate" in the 1970s had inspired a verdict by the Constitutional Court that before a permit is granted to an outpatient clinic, agreement is needed from regional medical associations. 
In Denmark, a key ingredient was the leadership of the central government (Frølich et al., 2008). A new National Board of Health created in 2007 issued several major health policy documents, including a national strategy on Chronic Disease Management. Eighteen health centres throughout the country were created with a focus on chronic care management and inter-sectoral co-operation.

The Ministry of Health and Prevention started a commission of primary care providers to develop recommendations for possible organisational changes in the primary care sector to support the new integrated care model. New initiatives were encouraged with financial support.

In Germany, similar chronic care initiatives have been supported with federal financial incentives. They are provided to social insurers, care providers, and patients, and have contributed to the rapid diffusion of these programmes in the country.

There is a financial incentive for sickness funds to participate in DMPs. For each patient participating in a DMP, the Fund receives a flat fee. There are also financial incentives for patients (exemptions from standard co-payments) and physicians (a lump sum payment for coordination and documentation). In 2009 , almost six million patients were enrolled in DMPs, and approximately $60-75 \%$ of eligible family physicians participated in such programmes.

Available evaluations indicate that German DMPs have significantly improved quality of care, with better clinical outcomes, and even reduced mortality. They are also cost-effective, as savings from avoided hospitalization are greater than other package costs (Borowitz et al., 2010). The 2004 and 2007 Health Reform Acts in Germany also provided for $1 \%$ of contract costs of Sickness Funds to be allocated to integrated care programmes.

In the Netherlands, policies are explicitly supporting the integration between primary and secondary services since 1990s, under the concept of "transmural care". The 2006 Health insurance reform introduced an additional innovation, in form of bundled payment schemes for chronic disease management. Integrated care groups (such as diabetes care groups) allow GPs to enter in joint contracts with health insurers, on basis of such bundled payments. As of January 2010, additional funding for the same type of programmes was made available, termed "patient-oriented funding". This encouraged co-operation between ambulatory and hospital care providers in chronic care groups, by permitting joint payment by health insurers (Groenewegen, 2009).

66. Progress in all these avenues, including consolidation of capacity planning, utilisation of performance-based payment mechanisms, better monitoring and enforcement of quality standards, and fostering transition to integrated care require not only federal government action, but also active co-operation and participation by the Länder governments and the Sickness Funds. The present institutional fragmentation of the system continues to make such strategic co-operation difficult, as in the past. In this environment, and taking into account the deeply-entrenched political and constitutional sources of fragmentation, all efforts should be made to consolidate public health resources around performance objectives. To achieve this, financing and spending responsibilities should be assigned more clearly than in the past. When such a clear division of responsibilities proves constitutionally impossible, "joint funds" ("fund pools") consolidating resources from different general government entities may be mobilised. For example, a "federal fund pool" can be created and utilised to help finance innovation and structural change in care supply, to better balance inpatient and outpatient services and to contain costs. In the longer term, a federal fund pool may also be put in charge of hospital investment across the territory, according to national plan objectives. A special fund can be put in charge of public health programmes. As a next step, after a fundamental change of financing structures, the operating costs of hospitals may also be fully paid by Sickness Funds, to which the tax resources (presently mobilised by federal and Länder governments for covering hospital costs) can be transferred. Overcoming the high fragmentation of the social insurance sector, by reducing the number of Sickness Funds, may also help. The Federation of Sickness Funds should continue to centralize functions where there are economies of scale. 


\section{Health care policy should also be supported by improvements in lifestyles}

\section{Lifestyles are not sufficiently supportive of good health outcomes}

67. The factors other than access to health care, but related to health-relevant lifestyles and preventive behaviour of the population, are important determinants of national health outcomes - and costs. This is increasingly better understood (OECD, 2010c). For example, alcohol consumption, smoking, sugar, salt and fat in diet, and exercising, exert a key impact on health outcomes, and costs, via a range of intermediary determinants of health status (the so-called "proximal risk factors") such as overweight, blood pressure, cholesterol levels, blood glucose levels, etc. ${ }^{36}$ For national policies aiming at enhancing the health status of the population, while keeping the cost of attaining these objectives under control, monitoring and improving these elements is crucial.

68. At first sight, standard health-related lifestyle elements in Austria do not differ significantly from OECD averages. They do not put Austria under a favourable light, but are not particularly deficient either. The incidence of overweight and obesity is, for example, slightly lower than OECD averages but higher for the 15 years-old. All in all, the net impact of these factors on life expectancy in Austria was estimated to be slightly negative - two to three months of lost life expectancy - reflecting principally above average alcohol consumption (Joumard et al., 2008).

69. At closer examination however, there are important sources of concerns. Three problem areas are alcohol consumption, smoking, and diet. Austria has one of the highest rates of alcohol consumption among the population above 15. Smoking rates remain at high levels, while they have declined in other countries. ${ }^{37}$ Austria has one of the lowest daily fruit eating among the 15 years old. Rates of physical activity are also below OECD averages. As a result, overweight rates have strongly increased in the 2000s, at a much higher pace than in most other countries. The increase in obesity rates was also above OECD averages.

70. An important factor behind these unfavourable outcomes, and which does not herald rapid improvement, is the disappointing health-related behaviour of young generations: Austria's smoking rate among 15 years-old is the highest in OECD, both for girls (30\%) and boys (24\%). The drunkenness indicators for the same age group are the fourth highest in OECD.

\section{Gaps in health-related lifestyles across social categories may become worrying}

71. An additional source of concern is the large gap in health-relevant lifestyles between different groups in the population. For example, differences in preventive behaviour are intriguingly large between the nine Länder (Figure 15). With respect to overweight and obesity, Austria has one of the highest rates of differentiation between occupation-based groups. Also, the gaps experienced by immigrant communities with low average levels of education appear particularly deep (Figure 16). Whereas equity of access to the healthcare system is a major national priority, such severe differentiation in health-relevant lifestyles risk counteracting this effort and provoking a worrying divergence in health outcomes. They could also seriously increase the health costs of the population groups concerned.

36. For instance, obese persons (with a body mass index between 30-35) experience much higher rates of cardiovascular diseases, diabetes and cancers. They incur health care expenditures at least $25 \%$ higher than normal weight persons. They also live two to four years less on average.

37. Smoking rates among adults in Austria in 2006 stood at 23.2\%, almost equal to the 2008 OECD average of $23.3 \%$ - while proactive countries such as the United States and Sweden managed to reduce it below $17 \%$. 
Figure 15. Health conditions and outcomes differ across Länder

2006
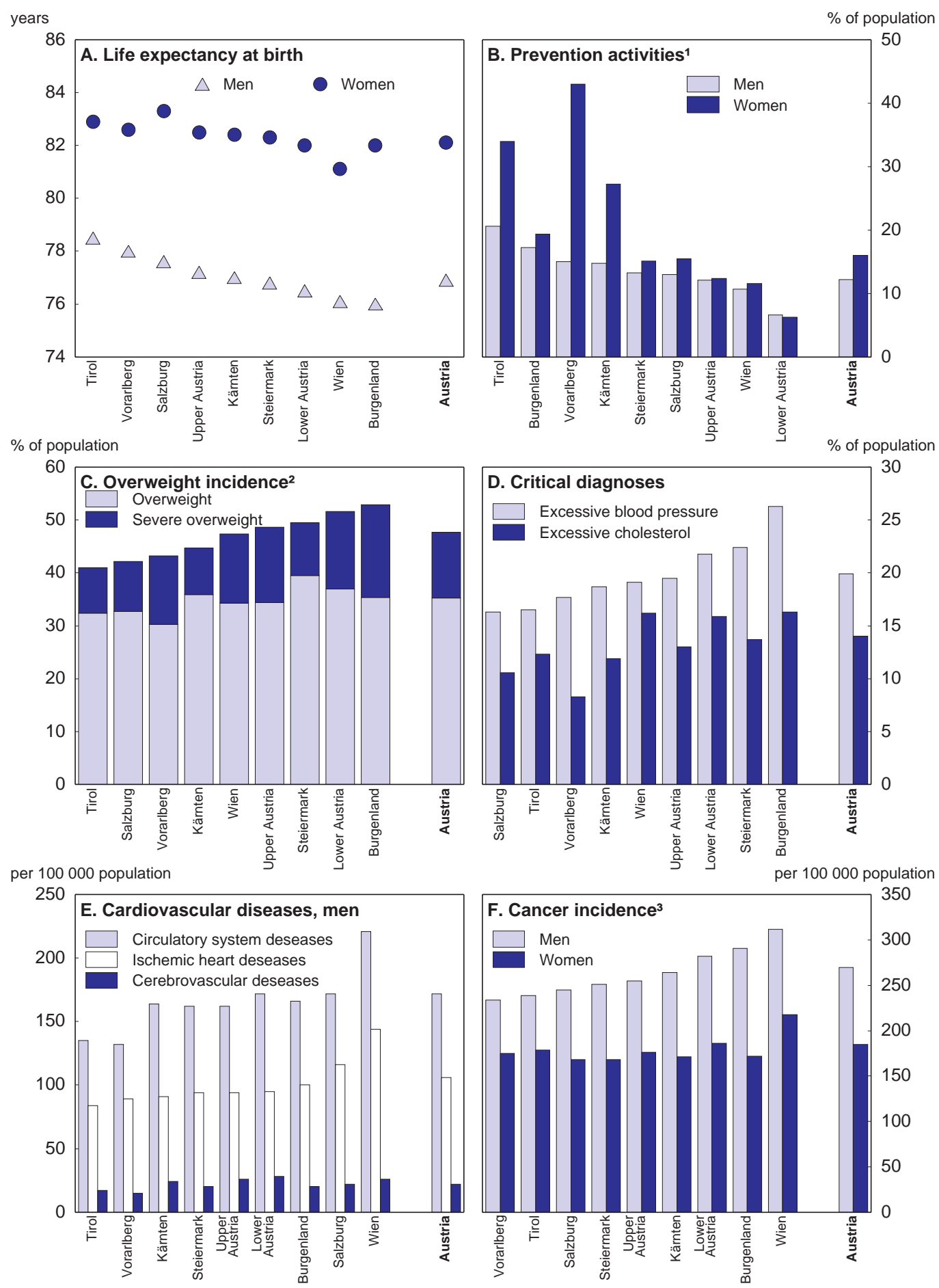

1. Percentage of population which participated each year in the voluntary national check-up programme between 2002-06.

2. Overweight is assessed by the body-mass-index (BMI). A BMl exceeding 25 but less than 30 refers to overweight and more than 30 to severe overweight.

3. All new cases of cancer per 100000 population.

Source: Gesudheit Österrich GmbH/Geschäftscbereich ÖBIG, "Monitoring 2007 zum Gesundheistsbericht Österreich 2004". 
Figure 16. Health-related behaviour differ between native and immigrant groups
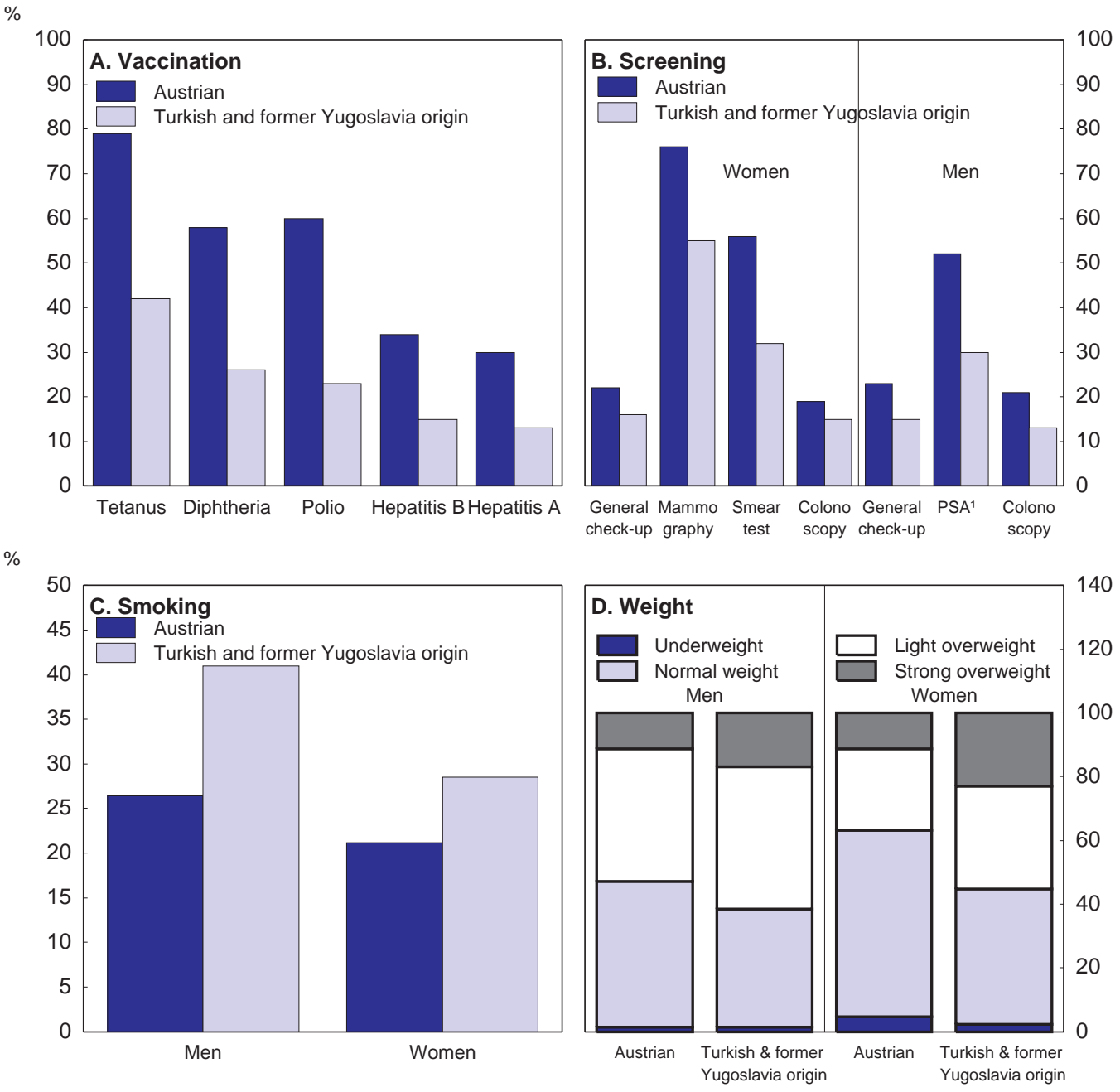

$\%$
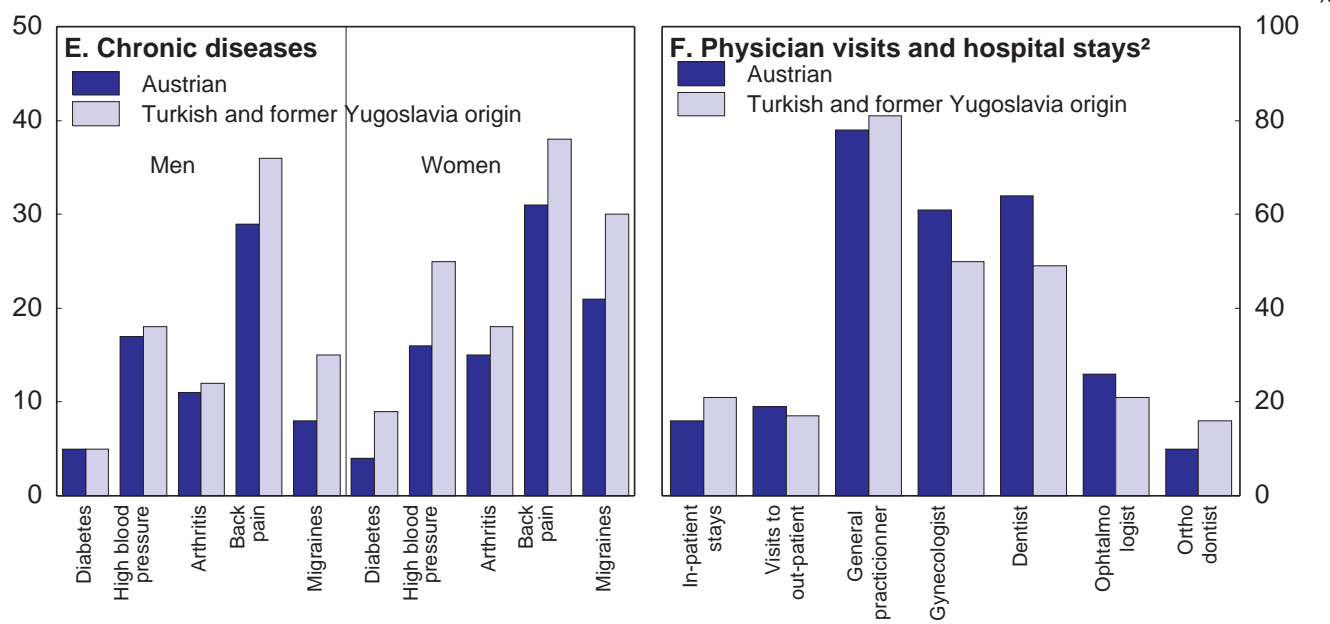

1. PSA - testicular cancer screening.

2. In the last 12 months.

Source: Statistik Austria, "Österreichische Gesundheitsbefragung 2007". 
72. Recent research showed that income-related health inequality has increased in Austria since 2005, while, in comparison to other countries, the level of this inequality has remained low (Eurostat, 2010). While the educational background of the population as a whole has improved, and a larger proportion has shifted to lower-risk groups, the difference between the health expectancy of women with a low level of education and those with a medium level of education has significantly increased (Klotz, 2010). Other determinants of these divergences, such as income level, ethnical or cultural origin, and other personal factors have not yet been thoroughly researched. If these differences in preventive behaviour and health-related lifestyles are not reduced, total health outcomes will fall short of potential, and the country will be unable to draw all the expected benefits from the high level of resources it is dedicating to the health system.

73. Such gaps may also have certain systemic implications in the future. Small proportions of individuals with particularly imprudent lifestyles risk generating disproportionally high health problems and costs. The Austrian system functions currently with unfailing social support to full risk pooling. It is estimated that in any given year, $1 \%$ of the population with the poorest health conditions receive $30 \%$ of total health insurance benefits; the $5 \%$ least healthy receive $60 \%$ of transfers, while the healthiest $50 \%$ consume $3 \%$ of total spending. Additional costs arising from unhealthy lifestyles should not undermine the valuable social consensus for risk pooling.

74. Austrian authorities are aware of the growing impact of the non-healthcare factors on health outcomes, and costs, and started to take related initiatives. The national prevention programme is being thoroughly re-assessed (see Annex A3). A "Dialogue on Children's Health" (Kindergesundheitsdialog) focuses on vulnerable children (Hofmarcher et al., 2010c). A National Action Plan diet (NAP.e) was launched in 2010, to help improve diet habits. The new Tobacco Act entered into force in January 2009, even if implementation seems to lag still behind. Similar campaigns in other countries delivered in many instances excellent results, which is encouraging for Austria. ${ }^{38}$

75. To achieve progress with health-relevant lifestyle factors, at the national level as well as for specific disadvantaged groups, quantitative "health goals" such as target rates of smoking, alcohol consumption, diet, etc., as well as in terms of "intermediary risk factors" such as body mass, blood pressure, blood glucose, cholesterol, etc. levels could be defined as benchmarks and targets for health policy. Monitoring them closely at national and regional level, as well as for specific groups, usefully informs policy.

38. Such as the Finnish Coronary Heart Disease Programme centered on dietary change which helped divide mortality rates from coronary diseases by four between 1971-95. 


\section{Policy recommendations}

76. The policy recommendations of the working paper are summarized in Box 7.

\section{Box 7. Policy recommendations}

Tighten the institutional design of the health system

- Public resources dedicated to health should be further consolidated and be given clear objectives, i.e. performance, financing and spending responsibilities should be much more clearly assigned in the national health system.

- The national capacity plan for publicly-funded inpatient and outpatient care should be optimized and enforced, under federal government authority, with the support of the Länder governments and Sickness Funds.

- In areas where a clear division of responsibilities between general government entities is constitutionally impossible, consolidate resources in "fund pools", and allocate them according to policy objectives. "Federal fund pools" helping re-balance care supply structures and contain costs, and to steer hospital investment across the territory would be examples.

- To increase policy leverage, the high fragmentation of Sickness Funds should be overcome. One possible step is to reduce the number of funds by merging them.

- The Federation of Sickness Funds (Hauptverband) should continue to centralize functions where there are economies of scale. It should continue to co-ordinate the participation of the social insurance sector to reform efforts.

\section{Mobilize performance-based payment mechanisms to improve productivity}

- Eliminate the firewalls between physicians' services and hospitals' outpatient wards and contract with both for ambulatory care, in order to trigger more user choice and competition.

- $\quad$ Base fee negotiations with all ambulatory care providers on more innovative cost-saving techniques, to help make converge fees with benchmark levels. Aim at gradually expanding the cost based hospital payment system DRG into outpatient care.

- $\quad$ Fully implement the DRG system on all inpatient services and close the loopholes which permit deviations of DRG payments from national cost benchmarks. As a next step - after a fundamental change of financing structures -, make Sickness Funds pay the full costs of inpatient care (on the basis of a transfer to the Sickness Funds of the tax resources currently allocated by federal and Länder governments to hospital costs).

- Increase competition in the pharmaceutical market by submitting not only new but also the existing 'stock' of drugs to health technology assessment, and by authorizing additional generic products when possible.

\section{Emphasise national health and quality goals}

- $\quad$ Set national health goals, such as quantified targets for obesity and overweight rates, blood glucose levels and cholesterol levels. Pursue them by a better balance between lifestyle improvement, prevention and curative care.

- Implement more effective public health programmes with respect to nutrition, smoking and alcohol consumption.

- Continue to develop "children's health" programmes which have positive life-long impacts. 
- Develop special programmes for vulnerable groups which lag behind in lifestyles and prevention, notably low education immigrant and resident groups.

- Implement fully the national quality strategy in the entire range of health services, if necessary on a stronger legal and regulatory basis.

\section{Promote better balanced integrated care}

- $\quad$ Continue to back disease management programmes (DMPs) and diffuse best practices in all chronic care areas.

- Remove legal restrictions for group practices, and for the outpatient departments of hospitals which could become autonomous entities. Do not restrict the ownership structures and employment practices of these operations.

- $\quad$ Authorise Sickness Funds to enter into managed care agreements with polyvalent group practices and outpatient clinics.

- $\quad$ Continue to give high priority to the development of the individual electronic health record-based ELGA system.

\section{Make the medium-term fiscal outlook of the system more prominent}

- Focus the post-crisis spending saving measures on structural areas, notably in the hospital sector.

- Make the official health and long-term care spending projections (presently produced in the context of the European Commission) more nationally visible.

- Integrate better the "health care" and "long-term care" components of projections, to better take into account growing demand for disability care.

- Produce national spending scenarios, with a full range of hypotheses on the impact of technological change and future demands for new services.

- $\quad$ Set a medium-term (10-15 years) path for public health spending at general government level.

- Consider making the public health spending at general government level a policy target associated with the multi-year budget framework which accompanies the annual budget law. 
ECO/WKP(2011)64

\section{Bibliography}

Auer, C. M. (2010), "Pharmaceutical country profile”, Gesundheit Österreich, Austria, Vienna.

Australian Institute of Health and Welfare (1997), First report on the national health priority areas, Canberra.

Bittschi, B. and M. Kraus (2007), "Implementation and Development of the E-card”, Health Policy Monitor, Institute for Advanced Studies (IHS), Vienna.

Borowitz, M. and M. Hofmarcher (2010), "Improving Co-ordination of Care for Chronic Diseases to Achieve Better Value for Money", in OECD Health Policy Studies: Value for Money in Health Spending, October 2010.

Bundesministerium für Gesundheit (Federal Ministry of Health) (2010), "The Austrian DRG system", brochure published by the Bundesministerim für Gesundheit., available at www.bmg.gv.at.

Cottarelli, C. et al. (2010), "Macro-Fiscal Implications of Health care reform in advanced and Emerging Economies -Case studies", Fiscal Affairs Department, IMF, Washington, DC.

Cutler, D. M. (2004), Your money or your life - Strong medicine for America's health care system, Oxford University Press.

Czypionka T. and G. Röhrling (2009), "Analysis of the 'reformpool'-activity in Austria: is the challenge met?", conference abstract, International Journal of Integrated Care, December.

Dranove, D. (2008), Code Red: an economist explains how to revive the health care system without destroying it, Princeton University Press, Princeton.

Erlandsen, E. (2007), "Improving the efficiency of health care spending: selected evidence on hospital performance", Economics Department Working Papers, No. 555, OECD, Paris.

Eurobarometer (2007), Health and Long-Term Care in the European Union, report, European Commission. Brussels, December.

Eurobarometer (2010), "Perceptions Regarding Quality of Healthcare”, Patient Safety, April.

European Commission (2009), The 2009 ageing report: economic and budgetary projections for the EU27 Member States (2008-2060), joint report prepared by the European Commision (DG ECFIN) and the Economic Policy Committee (AWG), EC, Brussels.

European Commission (2010), "Joint Economic Policy Committee - European Commission Report on Health Systems", Brussels, November. 


\section{ECO/WKP(2011)64}

Eurostat (2010), Analysing the socioeconomic determinants of health in Europe: new evidence from $E U-S I L C$, Publications Office of the European Union, Luxembourg.

Feachem, R., N. Sekhri and K. White (2002), "Getting More For Their Dollar: A Comparison of the NHS with California's Kaiser Permanente", British Medical Journal, 19 January.

Flandorfer, P. and K. Fliegenschnee (2010), "The gender gap in life expectancy in Austria: theoretical considerations based on a qualitative grounded theory study", Journal of Public Heath.

Frølich, A., M. Strandberg-Larsen and M.L. Schiøtz (2008), "The Chronic Care Model - A new approach in Denmark", Health Policy Monitor, April, available at www.hpm.org/survey/dk/a1 1/4.

Fujisawa, R. and G. Lafortune (2008), "The Remuneration of General Practitioners and Specialists in 14 OECD Countries: What are the Factors Influencing Variations across Countries?", OECD Health Working Papers No. 4, OECD, Paris.

Gaynor, M., R. Moreno-Serra and C. Propper (2011), "Hospital Competition and Patient Outcomes". The NBER Digest, National Bureau of Economic Research, January.

Glawischnig, M., G. Reichmann and M. Sommersguter-Reichmann (2009), “Austrian students and smoking: prevalence and characteristics", College Student Journal, June.

Groenewegen, P. (2009), "Towards patient oriented funding of chronic care", Health Policy Monitor, April 2009, available at www.hpm.org/survey/nl/a13/2.

Habl, C. and F. Bachner (2010), Das österreichische Gesundheitswesen im internationalen Vergleich, Ausgabe 2010, Österreichisches Bundesinstitut für Gesundheitswesen, Vienna.

Hauptverband (2010), "Masterplan Gesundheit“, mimeo, Vienna.

Health 21 (1999), "The health for all policy framework for the WHO European Region", European health for All Series, No. 6.

Hofmann, M.M. et al. (2010), "Healthcare and Financial Balance in 2014”, G-FAG Policy Brief, October.

Hofmarcher, M.M. (2009). "Patient safety on the rise?". Health Policy Monitor, October, available at www.hpm.org/survey/at/b14/1.

Hofmarcher, M.M. and H.M. Rack (2006), “Austria - Health system review”, Health systems in transition, $8(3): 1-247$.

Hofmarcher, M.M., B. Hawel and L.B. Tarver (2010c), "Let's talk kids: a dialogue for children's health", Health Policy Monitor, October, available at www.hpm.org/survey/at/al 6/1.

Hofmarcher, M.M., (2004), "Austrian Health Reform 2005: Agreement reached", Health Policy Monitor, available at www.hpm.org/survey/at/b4/1.

Hofmarcher, M.M., (2005a). "New rules for preventive health check-ups". Health Policy Monitor, 5. October 2005, available at www.hpm.org/survey/at/b6/2.

Hofmarcher, M.M., (2008). "Electronic Health Record: developments and debates". Health Policy Monitor, October 2008, available at www.hpm.org/survey/at/b12/1. 
Hofmarcher, M.M., (2010a), "Excess Capacity and Planning: Kain tortures Abel", Health Policy Monitor, April 2010., available at www.hpm.org/survey/at/a15/2.

Hofmarcher, M.M., B. Hawel (2010b). "Ambulatory care reforms fail to face the facts?" Health Policy Monitor, April 2010, available at http://hpm.org/survey/at/a15/1.

Hofmarcher, M.M., Ch. Lietz and A. Schnabl (2005), "Inefficiency in Austrian inpatient care: An attempt to identify ailing providers based on DEA results", Central European Journal of Operations Research, Vol. 13, Issue 4.

HOPE (2006), DRG as a Financing Tool, European Hospital and Healthcare Federation (HOPE), December.

Jenkner, E. and A. Leive (2010), "Health care spending issues in advanced economies", IMF, Fiscal Affairs Department, Washington, DC.

Joumard, I and U. Hakkinen (2007), "Cross-Country Analysis of Efficiency in OECD Health Care Sectors: Options for Research”, Economics Department Working Papers, No. 554, OECD, Paris.

Joumard, I., C. André and C. Nicq (2010), "Health Care Systems: Efficiency and Institutions", Economics Department Working Papers, No. 769, OECD, Paris.

Joumard, I., C. André, C. Nicq and O. Chatal (2008), "Health status determinants: lifestyle, environment, health care, resources and efficiency", Economics Department Working papers, No. 627, OECD, Paris.

Kelley, A.S. and D.E. Meyer (2010), "Palliative care - A shifting paradigm", The New Journal of Medicine, August.

Klimont J. (2005), “Gesunheitslebenserwartungen: Konzepte und Ergebnisse”, Statistische Nachrichten No. 2, Vienna.

Klotz, J. (2010), "Convergence or divergence of educational disparities in mortality and morbidity? The evolution of life expectancy and health expectancy by educational attainment in Austria in 1981-2006", Vienna Yearbook of Population Research, Vienna.

Langbein, K. (2009), Verschlusssache Medizin (Classified Medecine), Vienna.

Leopold, C. and C Habl (2008), "PPRI: Pharmaceutical pricing and reimbursement information", Austria Pharma Profile, Vienna.

Leutz, W. (1999), "Five Laws for Integrating Medical and Social Services: Lessons from the United States and the United Kingdom". The Milbank Quarterly, Vol. 77, No. 1.

LSE (2010), Public Health in Austria, London School of Economics, London.

Ludwig Boltzmann Institute - Health Technology Assessment (2009), Annual Report, Wien.

McKinsey Health Care Practice (1996), "Health care productivity", McKinsey Global Institute, Los Angeles, October. 


\section{ECO/WKP(2011)64}

Narath, M. (2010), “Lessons from 25 years health administration”, mimeo, Graz University Hospital, Graz, November.

Newhouse, J.P. (2002), ,Pricing the priceless - A health care conundrum, The MIT Press, Cambridge, MA.

OECD (2005 a), Economic Survey: Belgium, OECD, Paris.

OECD (2005 b), Economic Survey: Sweden, OECD, Paris.

OECD (2007), Improved Health System Performance through better Care Coordination, OECD, Paris

OECD (2008), Economic Survey: United States, OECD, Paris.

OECD (2009 a), Health at a Glance 2009: OECD Indicators, OECD, Paris.

OECD (2009 b), Economic Survey: Japan, OECD, Paris.

OECD (2009 c), Economic Survey: United Kingdom, OECD, Paris.

OECD (2009 d), Health Policy Studies: Achieving better value for money in health care, OECD, Paris.

OECD (2009 e), OECD Economic Survey: Austria, OECD, Paris.

OECD (2010 a), Health Care Systems: Efficiency and Policy Settings, OECD, Paris.

OECD (2010 b), Value for Money in Health Spending, OECD, Paris.

OECD (2010 c), Obesity and the Economics of Prevention: Fit not Fat, OECD, Paris.

OECD (2010 d), "Comparing price levels of hospital services across countries: results of a pilot study". Statistics Directorate Working Papers, No. 32, July, OECD, Paris.

OECD (2011 a), Economic Survey: Austria, OECD, Paris.

OECD (2011 b), Help Wanted? Providing and Paying for Long-Term Care, OECD, Paris.

Oliveira Martins, J. and Ch. de la Maisonneuve (2006), "The drivers of public expenditure on health and long-term care: An integrated approach", OECD Economic Studies, No. 2, OECD, Paris.

Oxley, H. and M. MacFarlan (1995), "Health Care Reform: Controlling Spending and Increasing Efficiency", OECD Economic Studies, No. 24, OECD, Paris.

Paris, V., M. Devaux and L. Wei (2010), "Health Systems Institutional Characteristics : A Survey of 29 OECD countries", Health Working Papers, No. 50, OECD, Paris.

Pearson, M. (2010), “Cures for Health Costs”, OECD Observer, October, OECD, Paris.

Pearson, M. (2011), Myths in Health Care Policies, mimeo, OECD, Paris.

Pfeiffer, K. P. (2009), "Future development of medical informatics from the viewpoint of health telematics", Methods Inf Med, 48. 
Pfeiffer, K.P. and C. Kobel (2009), "Financing inpatient health care in Austria”, Euro Observer, Vol. 11, No. 4, Brussels.

Pförtner, T-K and M. Richter (2011), "Getting social: Public Health's increasing awareness of the social determinants of health", Journal of Public Health.

Pichlbauer Ernest (2007), "Europas bestes Gesundheitssystem - der Mythos lebt", NÖ Edition, Patientenrechte, Vienna.

Rasky, É. (2008), "The Austrian health care reform 2005, new health care structures in Styria, Austria, and the medical training in health care provision at the Medical University Graz", Medicinski Glasnik, Vol. 5, No. 1, January.

Rasky, É., "A program for faculty and organisational development for the medical faculty of the University of Graz based upon an analysis of changed educational needs in the medical profession and society", undated mimeo, University of Graz, Graz.

Räty, T. and K. Luoma (2005), "Nonparametric country rankings using health indicators and OECD health data", mimeo, Helsinki.

Reichmann, G.and M. Sommersgutter-Reichmann (2003), "Co-payments in the Austrian social health insurance system - Analysing patient behaviour and patients' views on the effects of co-payments", Health Policy, 67(2004).

Retzlaff-Roberts. D., C.F. Chang and R.M. Rubin (2003), "Technical efficiency in the use of health care resources: a comparison of OECD countries", Health Policy, 69(2004).

Richards Mike (2010), Extent and Causes of International Variations in Drug Usage, A Report for the Secretary of State for Health, London.

Sanofi-Aventis (2009), “Gesundheitspolitik in Österreich 2009. Das Jahr in Rückblick”, Vienna.

Sanofi-Aventis (2010), “Gesundheitspolitik und Gesundheitswirtschaft in Österreich 2010. Das Jahr in Rückblick”, Vienna.

Schelling, H. J., "The Federation of Austrian Social Security Institutions as the Engine of Reform", undated mimeo, Vienna.

Sommersguter-Reichmann, M. (2000), "The impact of the Austrian hospital financing reform on hospital productivity: empirical evidence on efficiency and technology changes using a non-parametric input-based Malmquist approach", Health Care Management Science, Vol. 3, Issuee 4.

Statistics Austria (2007), Österreichische Gesundheitsbefragung 2006/2007, Statistics Austria, Vienna.

Statistics Austria (2010), Jahrbuch der Gesundheitsstatistik 2009, Statistics Austria, Vienna.

Stein, V.K. and A. Rieder (2009), "Lost in transition - meeting the challenge through integrated care: Highlights from the 9th International Conference on Integrated Care in Vienna", International Journal of Integrated Care - Vol. 9.

Trukeschitz, B. (2011), "Safeguarding good quality in long-term care: the Austrian approach", Eurohealth, Vol. 16, No. 2. 
WHO (1999), "Health21 - The health for all policy framework for the WHO European region", European health for all series, No. 6, World Health Organisation, Copenhagen.

Wild, C., M. Narath and W. Frank (2002), Evidenzbasierte Bedarfsplanung fur intensivbetten (Evidence based needs-planning for intensive-care beds), Institute of Technology Assessment of the Austrian Academy of Sciences, Vienna.

Wild, C. (2010), "Health technology assessment: oncology drugs with orphan designation as an example", Orphanet Journal of Rare Diseases, No. 5, published online 19 October. 
ECO/WKP(2011)64

\section{Annex A1}

\section{THE FUTURE OF THE HEALTH SYSTEM IN THE NATIONAL POLICY AGENDA}

The Austrian population displays a strong attachment to the health institutions, and is concerned about their future fate. A large Europe-wide survey in 2007 (Eurobarometer 2007) has reiterated the strong support of the population to the system.

The survey reveals that: $i$ ) in terms of perceived ease of access Austria ranks number one in Europe: $92 \%$ of the population find having easy access; ii) in terms of satisfaction Austria is ranked $2^{\text {nd }}: 92 \%$ of the population think that their system is very good or fairly good; iii) in terms of the affordability of the hospital care, Austria is in the top four group: $89 \%$ think that it is affordable; iv) concerning the quality of family doctors Austria is also among the top four, with $93 \%$ thinking it is good, accessible and affordable; v) on the quality of medical and surgical specialists Austria is $3^{\text {rd }}$, with $87 \%$ thinking the quality is very good or fairly good.

Perceptions are equally positive concerning the quality of long-term care, but mitigated concerning its availability and affordability. $41 \%$ find that long-term care services are not fully available, $56 \%$ think that they are not affordable. When asked if they will be provided with the necessary long-term care in the future, Austrians become the $8^{\text {th }}$ most pessimistic in Europe: $30 \%$ think that the needed services will not be available.

The latest Eurobarometer 2010 poll, which was a shorter update of the more comprehensive 2007 survey reiterated the same perceptions: In the area of the overall quality of health care Austria was ranked $2^{\text {nd }}$, with $95 \%$ of the population supportive. The Euro Health Consumer Index produced by Sweden's Health Consumer Powerhouse also confirmed the positive readings for existing health services. This index measures the user-friendliness of the national health systems - uniquely from a patient point of view. ${ }^{39}$ 38 criteria are applied. Austria had the $1^{\text {st }}$ place in 2007 , and the $4^{\text {th }}$ in 2009 , after the Netherlands, Denmark and Iceland. The relative weakening in 2009 was due to a missing unified benefit catalogue across the territory. The manager of the survey indicated that if such a catalogue was available Austria would regain its top position in Europe (Sanofi, 2009).

All in all, the Austrian population shows very strong support to the existing health services, but also appears to realize that the high concentration of public means in maintaining this system may make responding to new needs relatively difficult. In certain national surveys, more than $80 \%$ of respondents suggested that maintaining the quality of the public health system is today's most important national challenge. A majority indicated their readiness to contribute financially more to an effective public insurance system, rather than changing the balance between public and private coverage.

39. The technical basis of this ranking has been criticized, as in other opinion and satisfaction surveys which are not based on objective quality criteria. See Pilchbauer, 2007. 


\section{AUSTRIA'S PROGRESS WITH E-HEALTH TECHNOLOGIES}

Austria is building up an important information technology infrastructure for the health system.

First, in 2005, electronic billing was phased-in with the e-card. About 8 million people have an e-card, which is used as identification with providers. In addition to the billing function, the e-card is also used for authorization of certain services, mainly drugs. Total investment outlays for the roll-out of the e-card were in the order of EUR 110 million.

Second, the government made progress in implementing individual electronic health records (the ELGA system). Considering that market failures in the health sector could prevent patient-oriented e-health solutions from emerging, the authorities decided in 2006 that ELGA would be developed as a publicly financed infrastructure, encompassing all providers and patients. For this purpose, EUR 30 million for investment were made available.

While new policy initiatives to better integrate care have often disappointed in recent years, the government's e-health approach appears promising. It is strategically designed, and, in comparison to what other countries have achieved so far, appears comprehensive and inclusive. ${ }^{40}$ ELGA aims to support integrated provision of care across providers by documenting health related information of patients in a variety of data repositories. Data and information can be retrieved both by providers and by patients. This system will facilitate timely access to patient information by each provider, irrespective of where the provider is located. This will make health-related information centrally available, make it easier for patients to navigate the system, and ultimately has the potential to improve communication and coordination of care between sectors. It may also aid better targeting of vulnerable groups such as chronically ill patients. The e-card will be the electronic key to access patient information, and by 2012 it will be used to access relevant health-related information in various repositories. Patient access to their individual data will be possible via a web platform which was launched in 2010 (Austria Health Portal, see the main text).

In November 2009, a limited liability company (ELGA GmbH) was founded by all stakeholders. This organisation coordinates, builds and monitors the creation of all components necessary to run electronic exchanges across providers, and for access of patients. It is collaborating with European projects in this area.

In 2011, the first ELGA application will be run by using e-medication as a pilot. E-medication permits patients to have their doctors and pharmacists cross-check their medication record, on the basis of information stored on the e-card. The goal is to make drug therapy more effective and safe, by identifying interacting drugs or harmful dosages.

40. A particularly effective e-health record system, permitting to monitor individual health conditions, and adapt prevention and care strategies on an individual basis, is in use in California's Kaiser-Permanente health maintenance system (Feachem et al., 2002). ELGA has similar objectives. 
ECO/WKP(2011)64

\section{Annex A3 \\ SOME CHALLENGES WITH THE NATIONAL CHECK-UP PROGRAMME}

A risk of loss of quality arising from firewalls between care segments has been pointed out by Austrian health experts in the operation of the ambitious national check-up system. ${ }^{41}$

Austria is the only OECD country where free medical check-ups every three years are available for the entire population (about $40 \%$ of the population take advantage). In 2009, Austria-wide, about 970000 women and men (12\% of the population) participated in this screening programme. A comprehensive study by LSE carried out in 2010 for the Federation of Sickness Funds (Hauptverband) pointed to deficiencies in the design and implementation of this prevention package: according to this analysis the programme has a limited budget and a large part of this limited budget is spent on poorly-adapted procedures which do not target specific risk groups. The programme risks becoming a supply-pushed non-evaluated scheme, subject to risk of capture by special provider interests.

An illustrative problem is mentioned in the provision of one crucial function in check-ups: mammography screening for women. In this area, the Federation of Sickness Funds (Hauptverband) advocated and secured the principle of "double diagnoses", i.e. each mammography being followed by an ultra-sound examination in case of uncertainty of diagnosis. This practice may be in accordance with the EC guidelines. The EC, however, only recommends "second readings" of mammograms in case of uncertainty, before recourse to more strict and costly ultrasounds, and some Sickness Funds seem to differ in their interpretation of "uncertainty". Critical observers argue that present arrangements in Austria generate an unduly high proportion of false-positive mammograms, requiring far too many further investigations at excessive costs: $88 \%$ of all mammograms are accompanied by ultrasound examinations. They suggest that the designer of the prevention package (Federal Health Agency) did not decide on the basis of evidence-based medical merit, but under unilateral recommendations by service suppliers. They suggest that meeting quality standards in screening would save money for the Sickness Funds. Under the auspices of the Hauptverband, a new federal-wide programme is under construction.

41. LSE (2010) and testimony by Austrian health experts. 
ECO/WKP(2011)64

\section{WORKING PAPERS}

The full series of Economics Department Working Papers can be consulted at www.oecd.org/eco/workingpapers/

894 Greener growth in the Belgian federation

(September 2011) by Tomasz Koźluk

893. Green growth and climate change policies in New Zealand

(September 2011) by Alexandra Bibbee

892. Has deregulation increased investment in infrastructure? Firm-level evidence from OECD countries

(September 2011) by Sónia Araújo

891. Ensuring a Sustainable and Efficient Fishery in Iceland

(September 2011) by Gunnar Haraldsson and David Carey

890. Japan's New Growth Strategy to create demand and Jobs

(September 2011) by Randall S. Jones and Byungseo Yoo

889. Labour market reforms in Japan to improve growth and equity

(September 2011) by Randall S. Jones and Satoshi Urasawa

888. Education reform in Japan

(September 2011) by Randall S. Jones

887. The Political Economy of Climate Change Mitigation Policies: How to Build a Constituency to Address Global Warming?

(August 2011) by Alain de Serres, John Llewellyn and Preston Llewellyn

886. Climate-Change Policy in the United Kingdom

(August 2011) by Alex Bowen and James Rydge

885. Improving Access and Quality in the Indian Education System

(August 2011) by Sam Hill and Thomas Chalaux

884. How Institutions Shape the Distributive Impact of Macroeconomic Shocks: A DSGE Analysis

(July 2011) by Rudiger Ahrend, Charlotte Moeser and Tommaso Monacelli

883. Can India Achieve Double-Digit Growth?

(July 2011) by Richard Herd, Paul Conway, Sam Hill, Vincent Koen and Thomas Chalaux

882. Predicting peaks and troughs in real house prices

(July 2011) by Linda Rousová and Paul van den Noord

881. Public sector spending efficiency in Estonia: healthcare and local government

(July 2011) by Zuzana Smidova

880. How to move Product Market Regulation in New Zealand back towards the frontier (July 2011) by Paul Conway 
879. Financial sector reform in India: time for a second wave?

(July 2011) by Richard Herd, Vincent Koen, Ila Paitnak and Ajay Shah

878. Policies to rebalance housing markets in New Zealand (July 2011) by Calista Cheung

877. The sharing of macroeconomic risk: Who loses (and gains) from macroeconomic shocks (July 2011) Rudiger Ahrend, Jens Arnold and Charlotte Moeser

876. Estonia: making the most of globalisation

(June 2011) Robert Price and Andreas Wörgötter

875. The effects of downturns on labour force participation: evidence and causes (June 2011) Romain Duval, Mehmet Eris and Davide Furceri

874 A dynamic factor model for world trade growth (June 2011) Stéphanie Guichard and Elena Rusticelli

873. Towards a better understanding of the informal economy (May 2011) Dan Andrews, Aida Caldera Sánchez and Åsa Johansson

872. Tax competition between sub-central governments (May 2011) Hansjörg Blöchliger and José-Maria Pinero-Campos

871. The growth effects of current account reversals: the role of macroeconomic policies (May 2011) Luiz de Mello, Pier Carlo Padoan and Linda Rousová

870. Les politiques du logement en France (May 2011) Bénédicte Rolland

869. How important is wealth for explaining household consumption over the recent crisis? An empirical study for the United States, Japan and the euro area (May 2011) Clovis Kerdrain

868. Adjusting fiscal balances for asset price cycles (May 2011) Robert Price and Thai-Thanh Dang

867. Improving the functioning of the housing market in the United Kingdom (May 2011) Christophe André

866. An analysis of demand for foreign exchange reserves (May 2011) Peter Vujanovic

865. Episodes of large capital inflows and the likelihood of banking and currency crises and sudden stops

(May 2011) Davide Furceri, Stephanie Guichard and Elena Rusticelli

864. The effect of episodes of large capital inflows on domestic credit

(May 2011) Davide Furceri, Stephanie Guichard and Elena Rusticelli 